\title{
OS DESAFIOS DA REMEDIAÇÃO POR BOMBEAMENTO E TRATAMENTO EM DOMÍNIOS GEOLÓGICOS COMPLEXOS: O USO DE MODELOS ESTOCÁSTICOS PARA AUXILIAR NA DETERMINAÇÃO DA ZONA DE CAPTURA
}

\author{
Marcio Costa Alberto ${ }^{1}$, Kiang Hung Chang ${ }^{2}$
}

\begin{abstract}
RESUMO Em função da necessidade de remediação de áreas contaminadas, uma das técnicas utilizadas refere-se ao bombeamento e tratamento das águas subterrâneas, por meio da utilização de poços de bombeamento. Em áreas geologicamente complexas, a distribuição das litologias apresenta incertezas associadas à heterogeneidade. Neste estudo, foram realizadas simulações estocásticas (cadeias de Markov) e numéricas para avaliar as possíveis zonas de captura de um poço em bombeamento de uma área situada em Cubatão (SP), tendo em vista as distintas configurações espaciais das unidades litológicas locais, dado o nível de complexidade da geologia. A partir das simulações estocásticas foram gerados dez cenários geológicos distintos, que configuraram distintas zonas de captura. Sendo assim, os efeitos da heterogeneidade mostraram que, para a projeção de uma remediação por bombeamento e tratamento em áreas geologicamente complexas, deve ser considerada a abordagem das incertezas associadas à caracterização hidrogeológica, testando-se diversos arranjos espaciais litológicos, pois, quando se considera modelos simplistas, a remediação será ineficiente, aumentando os custos para novas investigações e ações de remediação adicionais.
\end{abstract}

Palavras-chave: simulação estocástica; simulação numérica; cadeias de Markov.

ABSTRACT Despite necessity of remediation of contaminated land, pump-and-treat is one of most used techniques, operating by pumping wells. In geologically complex areas, the distribution of lithologies shows uncertainties due to heterogeneity. In this study, were conducted stochastic simulations (Markov chains) and groundwater numerical modeling to evaluate possible capture zones of one pumping well at an area situated in Cubatão (SP), due to distinct local lithologies spatial distribution, according to complexity level of geology. Stochastic simulation results in ten distinct geologic scenarios, that configurate distinct capture zones. So, heterogeneities effects shows that, to pump-and-treat remediation design in geologically complex areas, must be considered the approach of uncertainties due to hydrogeological characterization, testing several lithologic spatial arrangement, because, when considering simplistic models, the remediation will be inefficient, charging fees to realize new investigations and additional remediation actions.

Keywords: stochastic simulation; numerical simulation; Markov chains.

\section{INTRODUÇÃO E OBJETIVOS}

A remediação de áreas contaminadas é tema de relevantes discussões e normatizações no cenário brasileiro, por meio de instrumentos legais ou normativos que definem os procedimentos para investigação e remediação destas áreas.

No momento de se definir a técnica e a configuração de um sistema de remediação, um dos fatores de relevante importância é a geologia, arcabouço hidrogeológico da área. Esta definição se torna ainda mais importante quando o domínio geológico estudado apresenta um grau elevado de complexidade, o que acarreta, muitas vezes, no insucesso da remediação pretendida.

$\mathrm{O}$ insucesso de uma remediação pode estar associado ao desconhecimento da geologia local e do comportamento hidrogeológico da área, em função da imprecisão na realização do diagnóstico da área, utilização de métodos e ferramentas equivocados, imperícia técnica em relação à caracterização hidrogeológica, e do conhecimento insuficiente das características da área.
Em ambientes geológicos complexos, a possibilidade de insucesso é muito maior, pois, as investigações realizadas, quase sempre, não são suficientes para delimitação determinística das características geológico-hidrogeológicas da área a ser remediada, onde se observam incertezas no conhecimento da área.

Consequentemente, a zona de captura de um poço em bombeamento é afetada diretamente pela distribuição das propriedades hidráulicas, o que também fica dificultado quando não se conhece o cenário geológico da área.

As incertezas inerentes à complexidade geológica, aliadas ao fato da comum imperícia na investigação de áreas contaminadas, se configuram pela proporção direta de uma investigação sem sistemática, inadequada ou incompleta, sendo que, ultimamente, visando à redução destas incertezas, vêm sendo utilizados modelos estocásticos para a definição dos possíveis cenários geológicos da área. Estes modelos estocásticos, aliados à modelagem numérica do fluxo da água subterrânea, 
auxiliam na determinação das possíveis zonas de captura neste ambiente geológico complexo, ou impropriamente conhecido.

Desta maneira, neste trabalho, foram realizadas simulações estocásticas, por meio de Cadeias de Markov, e utilizada modelagem numérica para avaliação da configuração hipotética da zona de captura de um poço em bombeamento, para remediação de uma área impactada por hidrocarbonetos derivados de petróleo, situada em Cubatão/SP (Figura 1), localizada em um domínio geológico complexo, em ambiente sedimentar de planície costeira-aluvionar, com sedimentação de depósitos gravitacionais, conferindo complexidade à hidrogeologia.

É importante ressaltar que esta metodologia também visa constituir uma ferramenta para contornar as dificuldades inerentes ou frequentes da realização de investigações exaustivas de uma área contaminada, situação encontrada no local selecionado para este estudo.
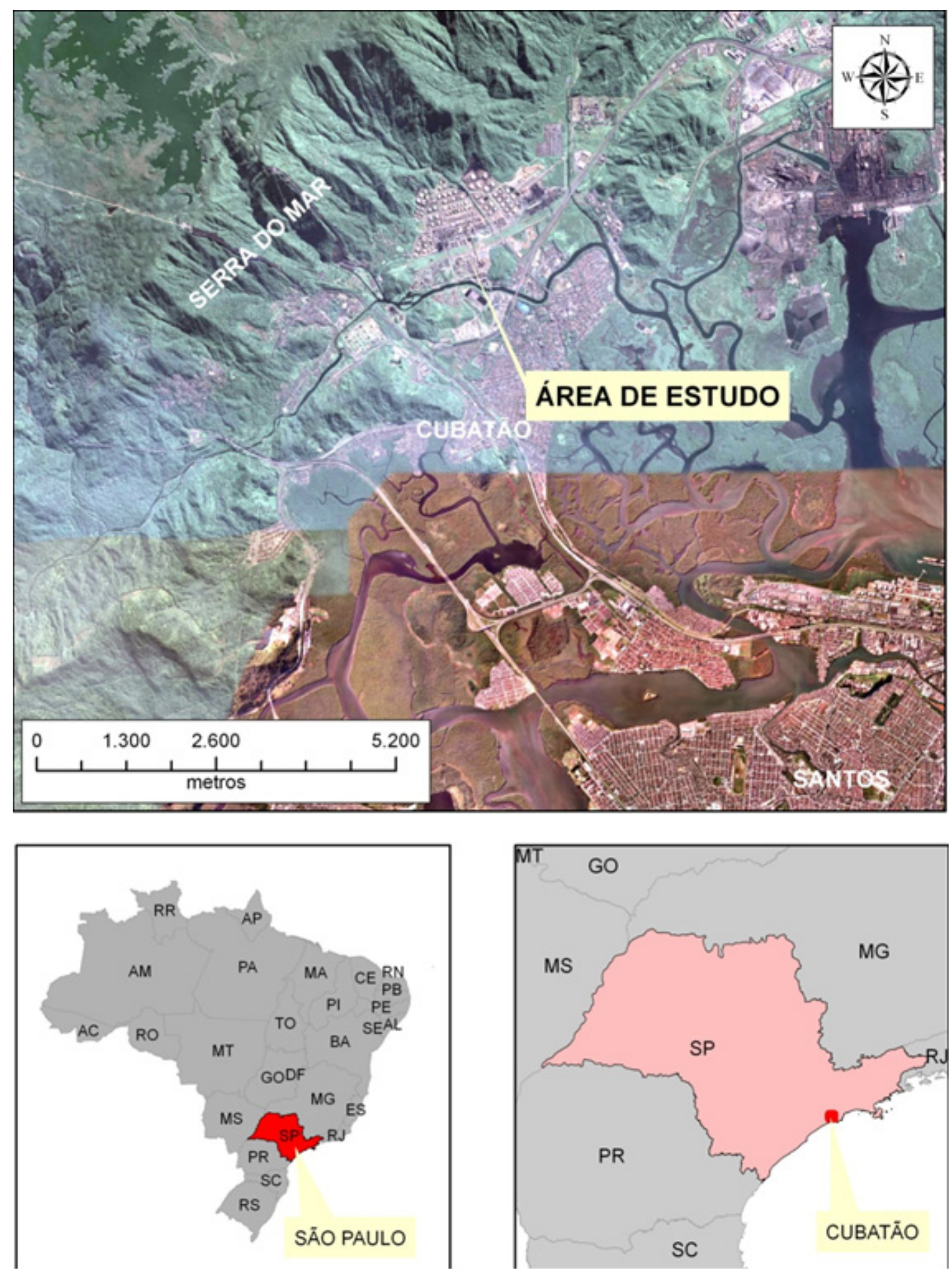

Figura 1. Localização da área de estudo. (ALBERTO, 2010) 


\section{MATERIAIS E MÉTODOS}

\subsection{Métodos/Procedimentos}

Para a realização desta pesquisa os procedimentos utilizados consistiram em:

a) Compilação de dados de campo:

(I) Sondagens à percussão (SPTs), para descrição litológica e definição dos hidrofácies;

(II) Dados de ensaios granulométricos, obtidos em sondagens ambientais realizadas na área de estudo, para auxiliar na definição dos hidrofácies; e

(III) Dados hidrogeológicos obtidos em poços de monitoramento, como: medições de nível d'água e ensaios hidrogeológicos para determinação da condutividade hidráulica.

b) Interpretação dos dados compilados para estabelecimento do modelo hidrogeológico conceitual e definição da área de interesse;

c) Realização de simulações estocásticas, para definição de 10 cenários com diferente distribuição da condutividade hidráulica;

d) Realização das simulações numéricas definição das zonas de captura; e

e) Comparação dos resultados obtidos.

O fluxograma da Figura 2 apresenta a sequência de etapas realizadas para o desenvolvimento desta pesquisa.

\subsection{MATERIAIS UTILIZADOS}

\subsubsection{Dados de campo}

Os dados de campo utilizados foram:

a) Sondagens à percussão: os dados foram obtidos de banco de dados de sondagens à percussão, realizadas na área de estudo, visando à obtenção de dados geotécnicos do local, para construção de edificações e instalações de unidade fabril atualmente existente no local. Os objetivos destas informações foram de descrição litológica e definição dos hidrofácies;

b) Sondagens ambientais: os dados destas sondagens, realizadas com fins de investigação ambiental, tiveram como função auxiliar a definição dos hidrofácies, por meio de:

(I) Descrição litológica; e

(II) Coleta de amostras para realização de ensaios granulométricos.

c) Poços de monitoramento: os dados dos poços de monitoramento tiveram como objetivo auxiliar na definição das características hidrogeológicas dos hidrofácies, tendo sido utilizados:

(I) Medições do nível d'água; e

(II) Ensaios de slug test realizados para determinação da condutividade hidráulica.

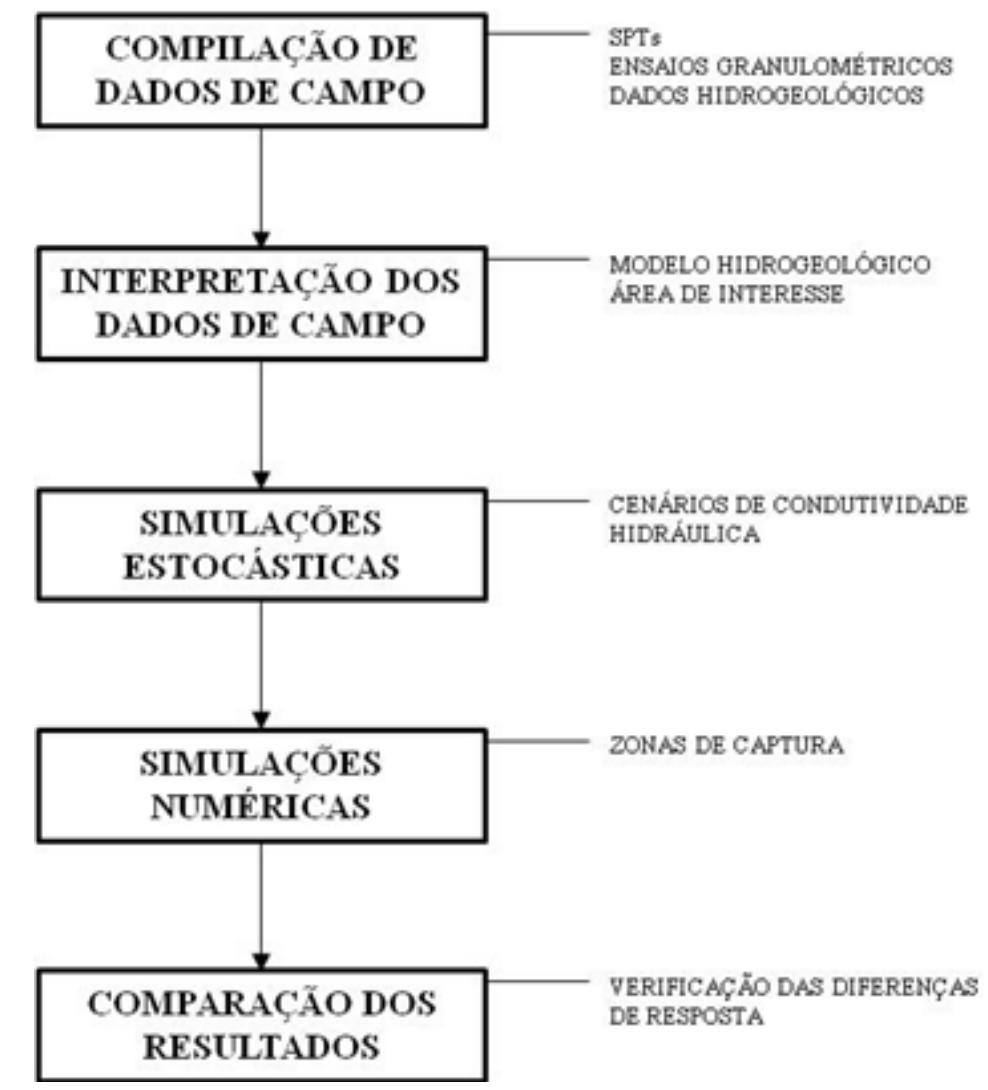

Figura 2. Fluxograma das etapas da pesquisa 


\subsubsection{Aplicativos}

O aplicativo T-PROGS, desenvolvido por Carle \& Fogg (1997), foi desenvolvido para a realização de simulações geoestatísticas, pela abordagem da probabilidade de transição.

Utilizando-se de dados litológicos de sondagens realizadas na área, em que se deseja avaliar a distribuição espacial destas litologias, para modelar a variabilidade espacial por meio de Cadeias de Markov e equações de co-krigagem indicativa, foi utilizado o aplicativo T-PROGS, o qual tem como princípio a formulação da função-objetivo para simulação por arrefecimento (annealing simulation).

Segundo Carle (1997), a implementação da simulação geoestatística envolve três passos principais:

(I) cálculo dos índices de probabilidade de transição;

(II) modelagem da variabilidade espacial por meio das Cadeias de Markov (CARLE \& FOGG, 1997) e;

(III) simulação estocástica condicional (CARLE \& FOGG, 1997).

As vantagens da utilização da probabilidade de transição em relação aos métodos tradicionais de krigagem indicativa são:

(I) considerar tendências assimétricas de justaposição, como por exemplo, sequências sedimentares granodecrescentes ascendentes;

(II) incorporar interpretações geológicas no desenvolvimento da correlação cruzada da variabilidade espacial, como plataforma conceitual de trabalho; e

(III) o ajuste da curva do modelo variográfico indicativo cruzado não é exclusivamente empírico, utilizando-se de modelo matemático simples e compacto, baseado nas Cadeias de Markov.

Estas vantagens são adequadas para a avaliação de dados geológicos, pois, o desenvolvimento de modelos espaciais baseados em dados geológicos, geralmente, somente é adequado na direção vertical, não permitindo a avaliação em planta.

A utilização das cadeias de Markov, neste tipo de estudo, é permitida pela correlação dos atributos fundamentais observáveis com os parâmetros do modelo matemático das cadeias de Markov, referentes a comprimentos médios, proporção de litologias, anisotropia e justa-posição.

A saída obtida por este aplicativo refere-se a $n$ conjuntos litológicos, em uma malha tridimensional (Figura 3), sendo que cada conjunto litológico $n$ está condicionado pelos dados das sondagens, e a proporção e transição das litologias entre as sondagens segue a tendência observada nas descrições litológicas destas sondagens.

Esta metodologia auxilia na interpretação geológica, bem como aprimora as correlações espaciais cruzadas, no desenvolvimento dos modelos geoestatísticos (CARLE, 1997).

Para o cálculo dos índices de probabilidade de transição $\left(t_{j k}\right)$ é utilizada a equação a seguir. Conforme a Figura 4, dada uma determinada propriedade ou valor de $j$, ocorrente em $x$, é determinada a probabilidade (Pr) de um valor ou propriedade $k$ ou mesmo a propriedade $j$, ocorrer na posição $x+h$.

$$
\boldsymbol{t}_{\boldsymbol{j} \boldsymbol{k}}(\boldsymbol{h})=\operatorname{Pr}\{\boldsymbol{k} \text { ocorrer em } \boldsymbol{x}+\boldsymbol{h} \mid \boldsymbol{j} \text { ocorrer em }
$$
$x\}$

A expressão da probabilidade pode ser apresentada como segue:

$$
\operatorname{Pr}\left\{B^{\prime} \mid A\right\}=\frac{\operatorname{Pr}\left\{A e B^{\prime}\right\}}{\operatorname{Pr}\{A\}}
$$

onde $\mathbf{A}$ representa $\{\boldsymbol{j}$, que ocorre em $\boldsymbol{x}\}$, e B' representa $\{\boldsymbol{k}$, que ocorre em $\boldsymbol{x}+\boldsymbol{h}\}$.

A simulação condicional tem como objetivo analisar a variabilidade espacial das propriedades hidráulicas gerando diversas realizações, as quais serão utilizadas para simulação numérica do fluxo da água subterrânea, identificando-se quais das realizações melhor se adequem às observações de campo e que apresentem os menores erros associados.

O objetivo de avaliar modelos estratigráficos e simulações estocásticas em conjunto é de obter-se um modelo hidrogeológico preciso, que possa representar melhor as condições reais observadas em campo. 


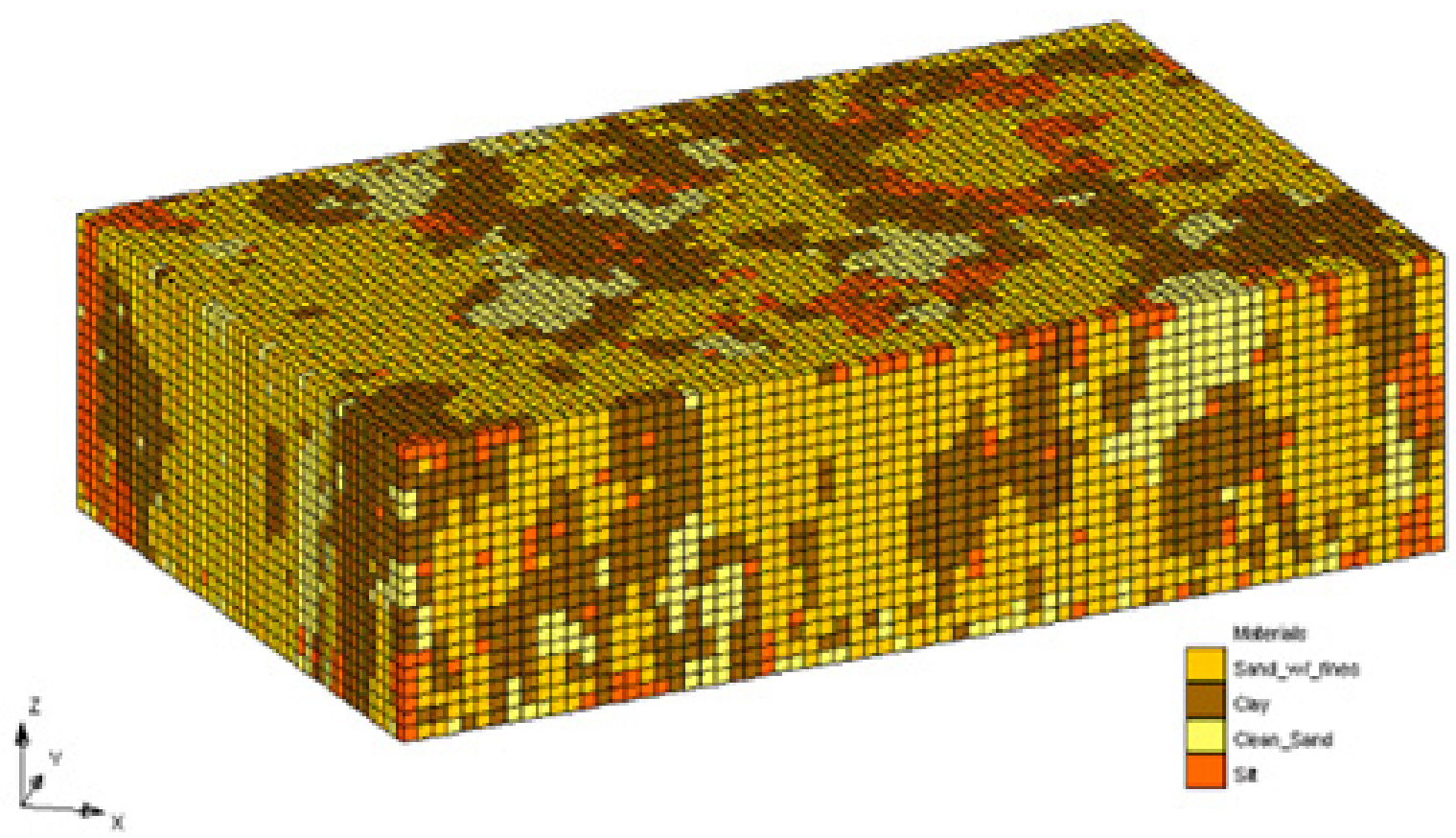

Figura 3. Distribuição tridimensional de materiais litológicos, simulados pelo T-PROGS. Disponível em $h t t p: / /$ www.ems-i.com/gmshelp/Interpolation/T-PROGS/T-PROGS_Interface.htm. Consultado em 21/04/2011.

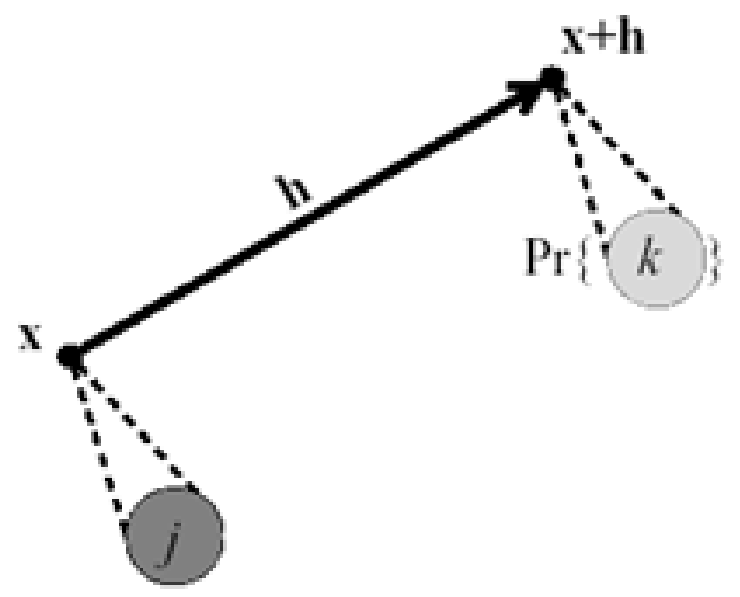

Figura 4. Representação gráfica da probabilidade de transição entre j e k. Fonte: Carle (1997)

Os dados das sondagens são introduzidos no aplicativo, indicando-se a posição tridimensional do material litológico presente, e a sua identificação por meio de números. Um utilitário associado ao T-PROGS, GAMEAS, calcula um conjunto de curvas de probabilidade de transição dos materiais litológicos presentes (Figura 5), em função de uma distância do passo (lag) para cada categoria em um determinado intervalo de amostragem, sendo que cada curva apresentada representa a probabilidade de transição do material $j$ para o material $k$.

As curvas na diagonal representam as probabilidades de auto-transição e as demais curvas representam as probabilidades de transição cruzada.

O próximo passo é o desenvolvimento do modelo pela Cadeia de Markov na direção vertical ajustada aos dados da probabilidade de transição vertical observados. 


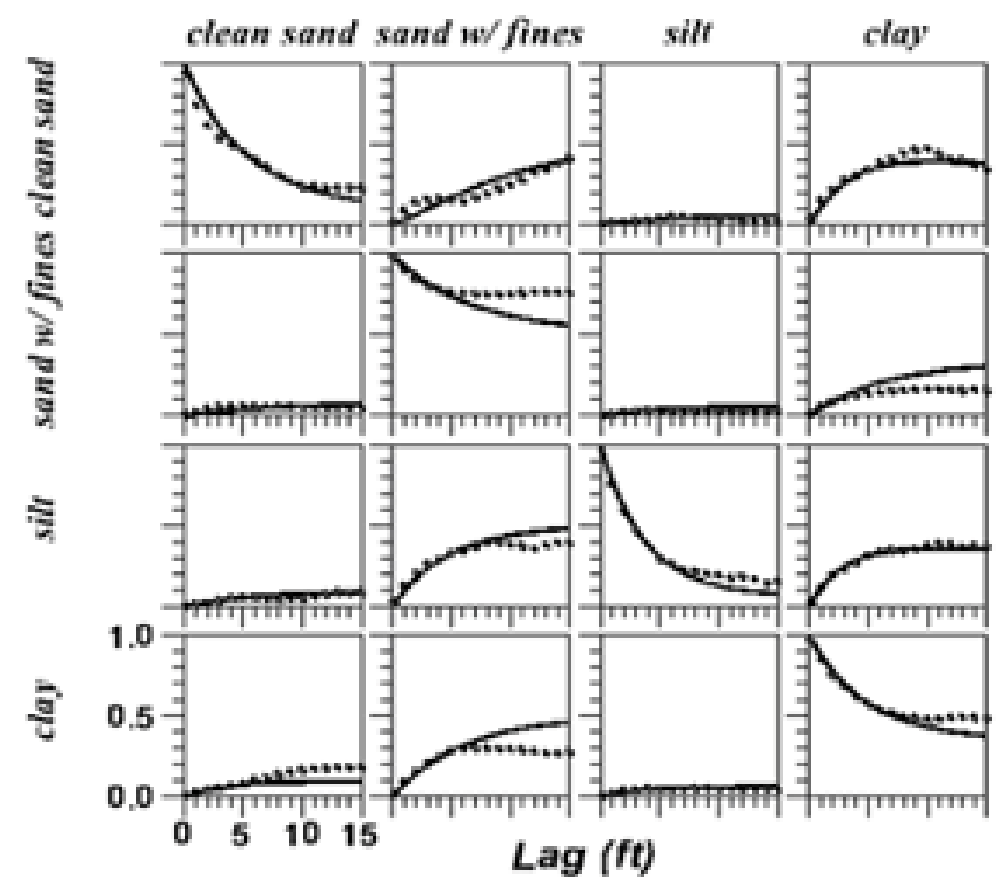

Measured

Markov Chain

Figura 5. Conjunto de curvas de probabilidade de transição. Fonte: Disponível em

http://www.ems-i.com/gmshelp/Interpolation/T-PROGS/T-PROGS_Interface.htm. Consultado em 21/04/2011

As curvas das cadeias de Markov são mostradas pelas linhas sólidas na Figura 5. Matematicamente, o modelo por cadeias de Markov, quando aplicados a dados categóricos unidimensionais na direção $\phi$, assumem a forma de matriz exponencial, conforme mostrado a seguir:

$$
T\left(h_{\phi}\right)=\exp \left(R_{\phi} h_{\phi}\right)
$$

onde $h$ denota um passo (lag) na direção $\phi$, e $R \phi$ denota a matriz de valores de transição:

$$
R_{\phi}=\left[\begin{array}{ccc}
r_{11, \phi} & \mathrm{L} & r_{1 k, \phi} \\
\mathrm{M} & \mathrm{O} & \mathrm{M} \\
r_{k 1, \phi} & \mathrm{L} & r_{k k, \phi}
\end{array}\right]
$$

com as entradas $r j k, \phi$ representando a taxa de mudança da categoria $j$ para a categoria $k$ (condicionada pela presença de $j$ ), por unidade de comprimento na direção $\phi$.

As taxas de transição são ajustadas para garantir a melhor correlação entre o modelo por cadeias de Markov e os dados de probabilidade de transição observados.

Uma vez que foi desenvolvido o modelo por cadeias de Markov para a direção $z$, a partir dos dados das sondagens, um modelo de variabilidade espacial deve ser desenvolvido para as direções $x \mathrm{e}$ $y$, salientando que os dados de sondagens são tipicamente insuficientemente densos nestas direções.

Entretanto, o modelo por cadeias de Markov pode ser desenvolvido nestas direções assumindo-se que as tendências de justaposição e as proporções observadas na direção vertical também são verdadeiras nas direções horizontais, $x$ e $y$, sendo necessário o estabelecimento de estimativas da razão do comprimento médio nas direções $x$ e $y$ relativos à direção vertical, $z$, permitindo-se o cálculo das matrizes de valores de transição para as direções horizontais.

As cadeias de Markov nas direções $x, y$ e $z$ são então convertidas para um meio contínuo tridimensional, baseado em cadeias de Markov, utilizando-se o aplicativo MCMOD.

Finalmente, na definição dos parâmetros da análise de probabilidades de transição, utilizandose o aplicativo T-PROGS, cria-se uma malha, especificando o número de conjuntos $n$ de arranjos requeridos, rodando-se o aplicativo TSIM, o qual 
se utiliza do meio contínuo tridimensional baseado em cadeias de Markov para criar as equações da cokrigagem indicativa e a função objetivo da simulação por arrefecimento (annealing simulation), gerando as simulações estocásticas por meio da combinação de versões modificadas dos códigos SISIM e ANNEAL do pacote geostatístico GSLIB.

Os passos descritos anteriormente foram utilizados para as simulações apresentadas no item a seguir, referentes ao estabelecimento dos arranjos espaciais da litologia, bidimensional, para a simulação das possíveis zonas de captura de um poço em bombeamento, em dez cenários distintos de distribuição litológica no local selecionado para avaliação.

\section{ZONAS DE CAPTURA E CADEIAS DE MARKOV}

De acordo com USEPA (2008), a zona de captura de um ou mais poços em bombeamento, incluídos drenos e poços dispostos para constituição de uma barreira hidráulica, refere-se à região tridimensional que contribui para a extração de água do aquífero.

A Figura 6 mostra a representação de uma zona de captura para um poço de bombeamento parcialmente penetrante, onde se observa que a região de captura vertical não abrange todo o aquífero, mostrando a necessidade de investigações detalhadas para que se possa ter uma estimativa mais precisa desta zona.
O dimensionamento impreciso da zona de captura de poços utilizados para remediação pode ocasionar na fuga de contaminantes, com a possibilidade de atingir os receptores que estariam sendo protegidos pela remediação prevista (Figura 7).

Para Kinzelbach et al. (1996), o formato e a dimensão de uma zona de captura não pode ser determinada com exatidão em função das incertezas inerentes aos parâmetros do aquífero e da recarga (Figura 8). Para tanto, estes autores aplicaram o método estocástico de Monte Carlo para determinação da distribuição da transmissividade e da recarga em um aquífero heterogêneo, obtendo-se diferentes zonas de captura, para distribuições distintas dos parâmetros do meio físico. Estes autores também identificaram que, com o aumento da disponibilização de dados, as incertezas reduziam consideravelmente.

Outros autores também utilizaram simulações estocásticas para solução de problemas hidrogeológicos, referentes à zona de captura e perímetros de proteção de poços, sendo estes van Leeuwen et al. (1999), Cole \& Silliman (2000), Copty \& Findikakis (2002), Ahern et al. (2003), Lu \& Zhang (2003), Zhang \& Lu (2004), Indelman et al. (2006), entre outros.

Conforme dados compilados por Alberto (2010), em dados da área de estudo, a distribuição das propriedades do meio é condicionada diretamente pelos processos geológicos que formaram as unidades hidrofaciológicas presentes.

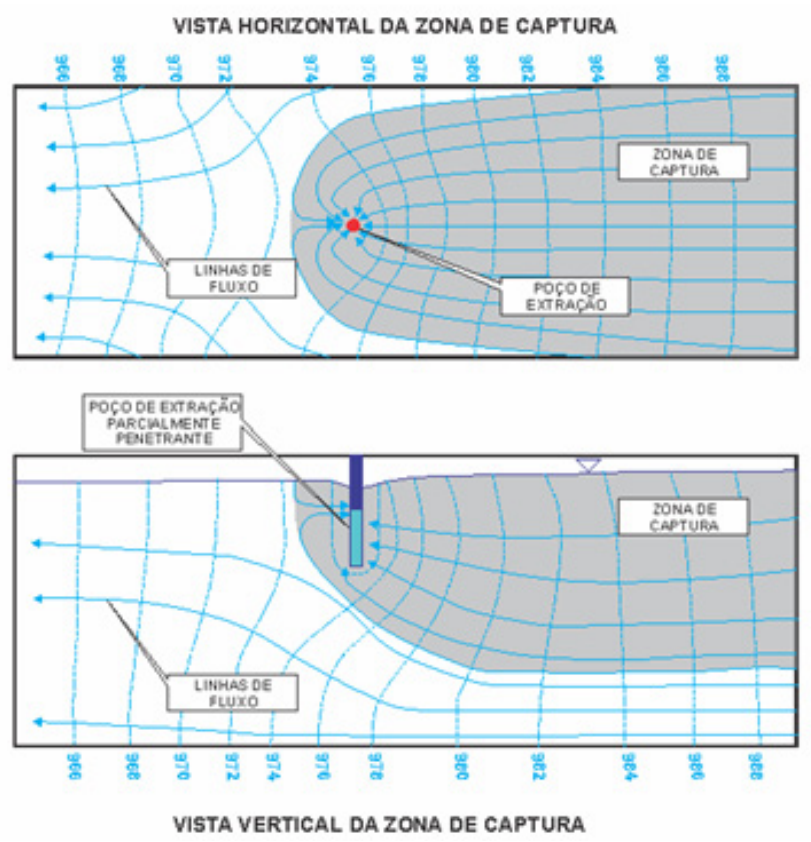

Figura 6. Vistas em planta e em seção longitudinal de uma zona de captura de um poço de bombeamento. Fonte: USEPA (2008) 


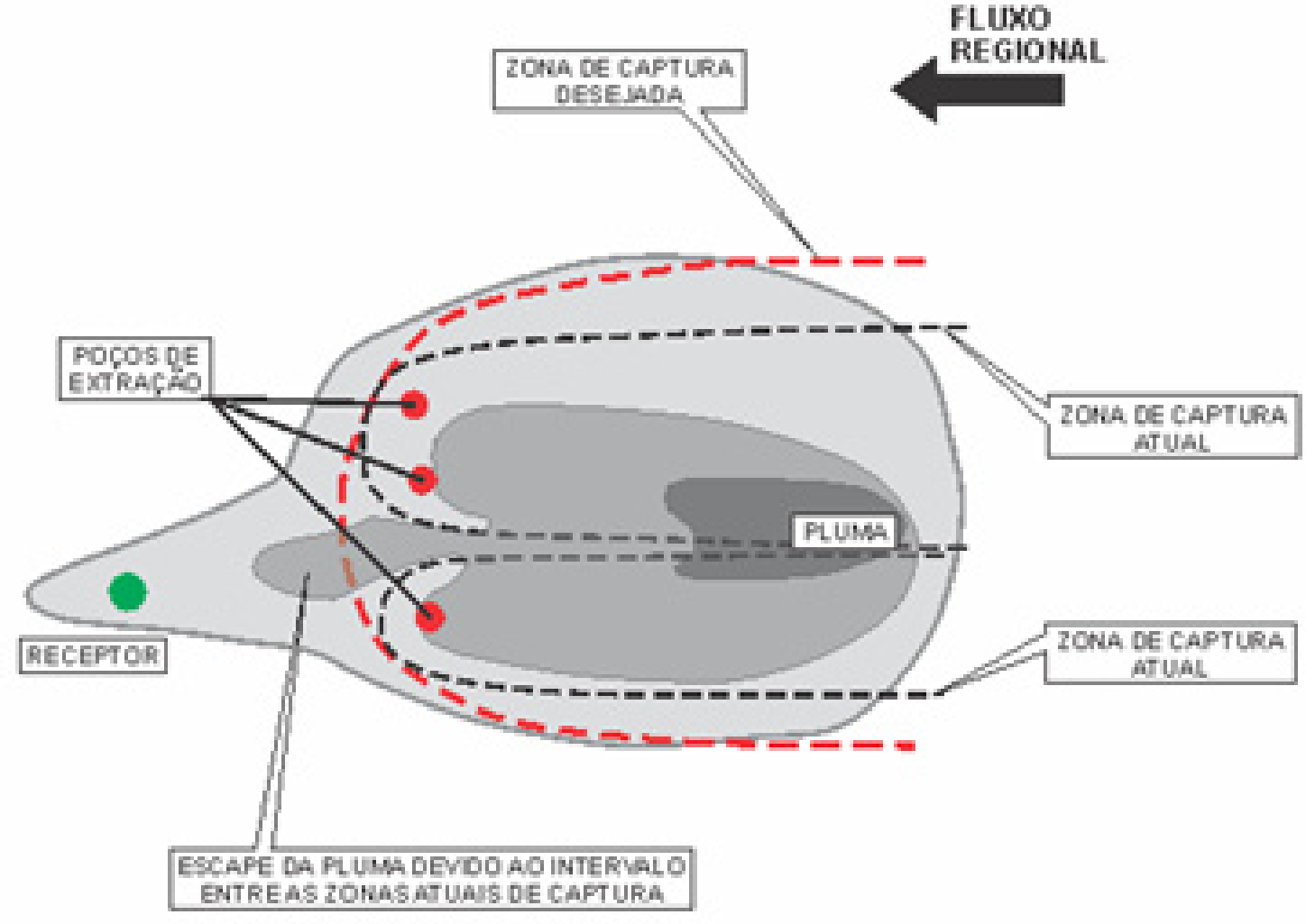

Figura 7. Pluma escapando por zona de captura subdimensionada em uma barreira hidráulica. Fonte: USEPA (2008)
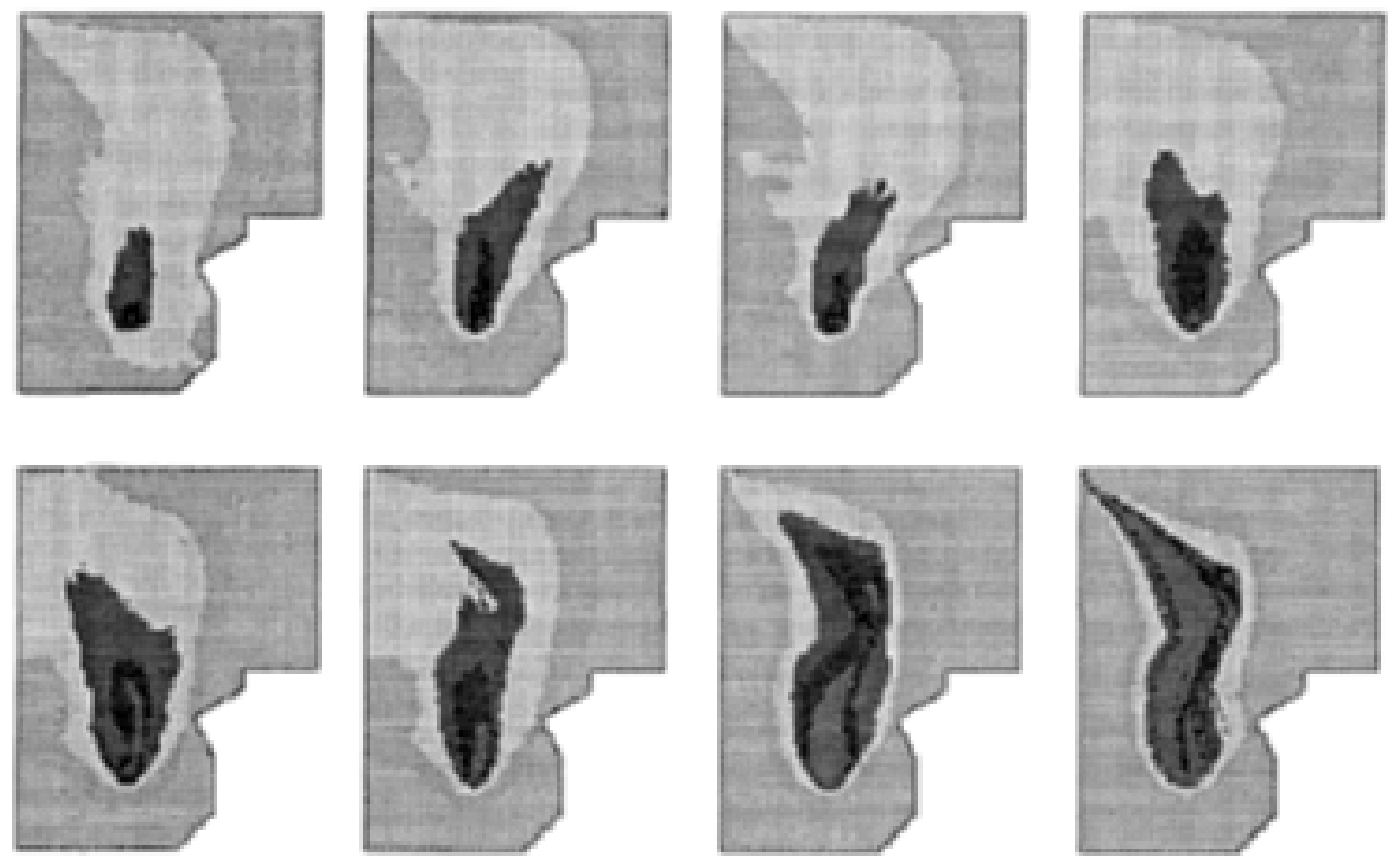

nis.

Figura 8. Zonas de captura de poços de extração de água subterrânea definidas por simulações estocásticas. Fonte: Kinzelbach et al. (1996) 
Estas unidades têm origem associada à ambientes sedimentares diversos, predominantemente por depósitos aluvionares, com ocorrência de sedimentos de canal e de várzeas, interdigitados a depósitos de corridas de massa provenientes das encostas da Serra do Mar.

Desta forma, Alberto (2010) verificou que, dificilmente, os modelos determinísticos poderiam representar, adequadamente, a distribuição exata destas unidades, a depender da escala de estudo, tendo diversas possibilidades de arranjo espacial das mesmas no local, com base nos mesmos dados disponíveis.

Para estes tipos de ambientes deposicionais, de acordo com Sharp et al. (2003), os fácies sedimentares refletem seu ambiente deposicional original. Também, definem as tendências, dimensões, conectividades e as heterogeneidades internas das zonas transmissivas em aquíferos clásticos.

Neste contexto, a heterogeneidade está associada à variabilidade espacial da permeabilidade, causada pelas variações texturais nos sedimentos aluvionares.

Segundo estes autores, existem três estilos de heterogeneidade - camada de bolo (layer cake), quebra-cabeças (jigsaw puzzle) e labirinto (labyrinth), conforme mostrado na Figura 9, os quais refletem um aumento no grau de complexidade da geologia local. Estes estilos são determinados pela origem, forma e evolução deposicional dos materiais do aquífero.
As heterogeneidades macroscópicas, que ocorrem na escala deposicional de fácies, definidas por estes autores, incluem a compartimentalização das litologias; gradientes de permeabilidade vertical e lateral originados pelos padrões de tamanho, seleção e arranjo dos grãos; e estratificação de sedimentos finos de baixa permeabilidade, os quais podem definir vários padrões ou orientações de fluxo, sendo criada a anisotropia.

Para estes autores, todas as escalas de estruturas heterogêneas podem ser descritas, quantificadas, interpoladas e, por vezes, previstas conforme o arcabouço de seu sistema deposicional e pode ser subsequentemente modificado pela diagênese.

$\mathrm{O}$ arcabouço do sistema deposicional e suas modificações refletem diretamente nos valores de condutividade hidráulica das unidades que a compõem.

A utilização de modelos estocásticos, baseados em Cadeias de Markov, para a solução de problemas hidrogeológicos é crescente na última década, onde diversos autores apresentaram publicações referentes a esta metodologia, principalmente para sistemas aquíferos aluvionares.

Elfeki et al. (1997), cita, de forma abrangente, o tema de incertezas associadas à heterogeneidade, com ênfase para os métodos estocásticos na determinação das propriedades do meio físico, principalmente quanto à utilização de Cadeias de Markov, em problemas específicos de contaminação de águas subterrâneas.
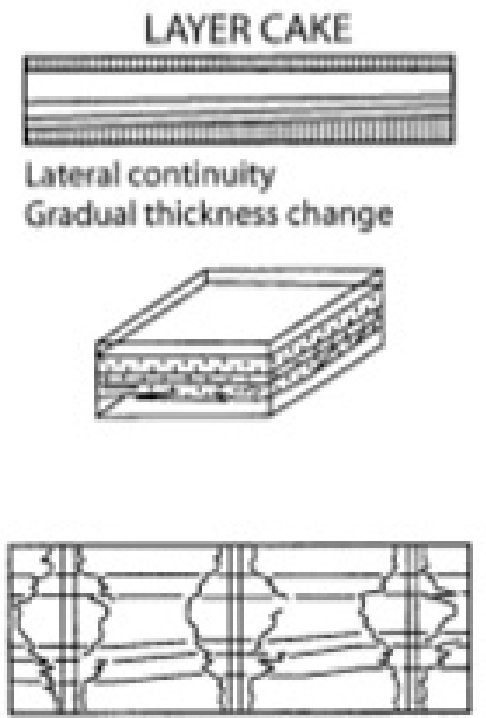

Extemal and internal correlation simple

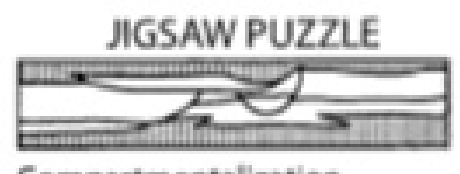

Compartmentalization Abrupt textural ( $\mathrm{k}$ ) contacts
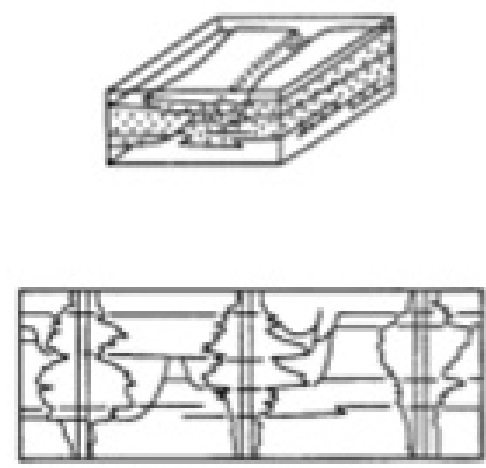

External correlation simple: internal correlation difficult
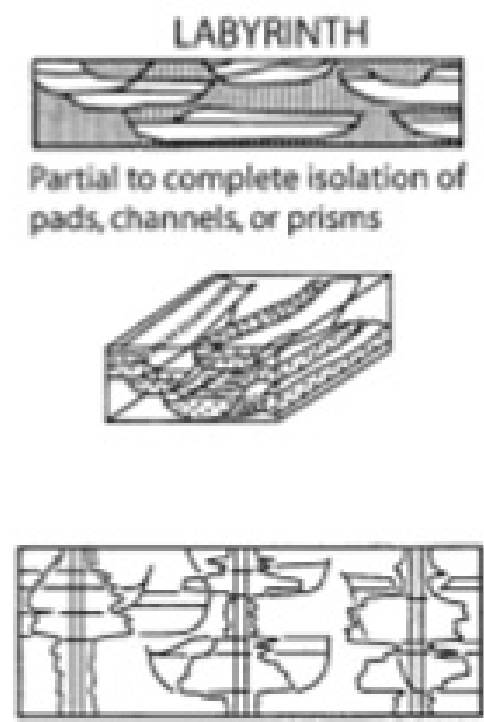

External and internal correlation difficult

Figura 9. Estilos de heterogeneidades em ambientes sedimentares aluvionares. Fonte: Sharp et al. (2003) 
Rijud et al. (2000), utilizaram a abordagem de probabilidade de transição por cadeias de Markov, para a representação estocástica de sedimentos de canal com alta permeabilidade, em uma sequência aluvionar. O modelo foi considerado como apropriado para o gerenciamento de riscos de forma conservadora, para os tempos de chegada de soluções salinas, onde apenas foi considerado o transporte pelos depósitos de canais, enquanto que os processos de difusão e transporte em unidades menos permeáveis foi negligenciado.

$\mathrm{Lu}$ et al. (2000) desenvolveram o método conjugado de Cadeias de Markov e Monte Carlo (MCMC - Markov Chain Monte Carlo) para estimar a distribuição da condutividade hidráulica na área aplicada, condicionado por medições diretas deste parâmetro a variáveis como carga hidráulica na zona saturada em um meio poroso aleatoriamente heterogêneo.

Segundo Weissmann (2005), a heterogeneidade das propriedades hidráulicas, em diversas escalas de observação, em um aquífero aluvionar, é consideravelmente controlada pela distribuição dos fácies sedimentares associadas a este ambiente. Para tanto, os autores utilizaram modelos estratigráficos e sedimentológicos quantificáveis para incorporar esta variabilidade espacial das propriedades hidráulicas em simulações de fluxo da água subterrânea e de transporte e migração de contaminantes.

A abordagem utilizada por Weissmann (2005) utiliza-se dos conceitos de estratigrafia de sequências, desenvolvida para ambiente sedimentar de delta aluvionar continental para:

(I) delinear as unidades estratigráficas, em escala regional, do aquífero aluvionar;

(II) prever os padrões gerais de fácies do aquífero e;

(III) subsidiar o desenvolvimento de modelos de cadeias de Markov para a geoestatística de probabilidade de transição.

Os resultados das simulações geoestatísticas foram utilizados por Weissmann (2005) para simulações do fluxo da água subterrânea, com o objetivo de definição da distribuição da idade da água subterrânea, avaliar estratégias de remediação e modelar a configuração de testes de aquífero, em um contexto heterogêneo.

Desta maneira, o autor ressalta que, por meio desta abordagem, os geólogos puderam quantificar as interpretações geológicas conceituais e apresentar comportamentos da heterogeneidade subsuperficial que, razoavelmente, reflete as características complexas da estratigrafia de aquíferos aluvionares.

\section{CARACTERIZAÇÃO DA ÁREA DE ESTUDO}

\subsection{GEOLOGIA REGIONAL}

A área de estudo está situada na Serra do Mar (Bloco São Paulo), que faz parte do "Sistema Rift do Leste Brasileiro" - SRLB (Figura 10) assim denominado por Chang et al. (1992). Este constitui o segmento setentrional do "Sistema Rift do Atlântico Sul" - SRAS, conforme Almeida (1976) e Riccomini (1987). Este rifte se formou durante a era Mesozóica, separando os continentes da América do Sul e da África, os quais pertenceram ao Supercontinente Gondwana.

O SRLB faz parte da margem leste do Bloco América do Sul, resultante de deslocamentos crustais de caráter extensivo, formando vales de subsidência de paredes paralelas, alongadas e íngremes, constituídos por horsts e grabens alinhados segundo direção NE-NNE, aproximadamente subparalelos aos lineamentos principais do Embasamento Cristalino (CHANG et al., 1992).

Na porção da área de estudo, mais precisamente na Serra de Cubatão, o SRLB possui direções predominantes de lineamento de N55-60E, com conjunto subsidiário de direção de N45-55W (CHANG et al., 1992).

Nesta província, as rochas foram extremamente afetadas pelo metamorfismo do Ciclo Brasiliano, recortada por intenso cisalhamento transcorrente, associado aos estágios de convergência de blocos continentais, quando, então, foi gerado o "Sistema de Megafalhas de Cubatão/ Além-Paraíba" (SADOWSKI \& MOTIDOME, 1987; SADOWSKI, 1991).

Durante o Terciário-Quaternário, a evolução da paisagem transformada pela formação do SRLB originou a deposição de sedimentos costeiros e marinhos, estando a área de estudo na zona de transição entre a Serra do Mar e a Planície Sedimentar Costeira.

As unidades geológicas existentes na área, segundo Hasui et al. (1995) e Suguio \& Martin (1994), são representadas por rochas do Embasamento Cristalino e por Sedimentos Terciário-Quaternários. 


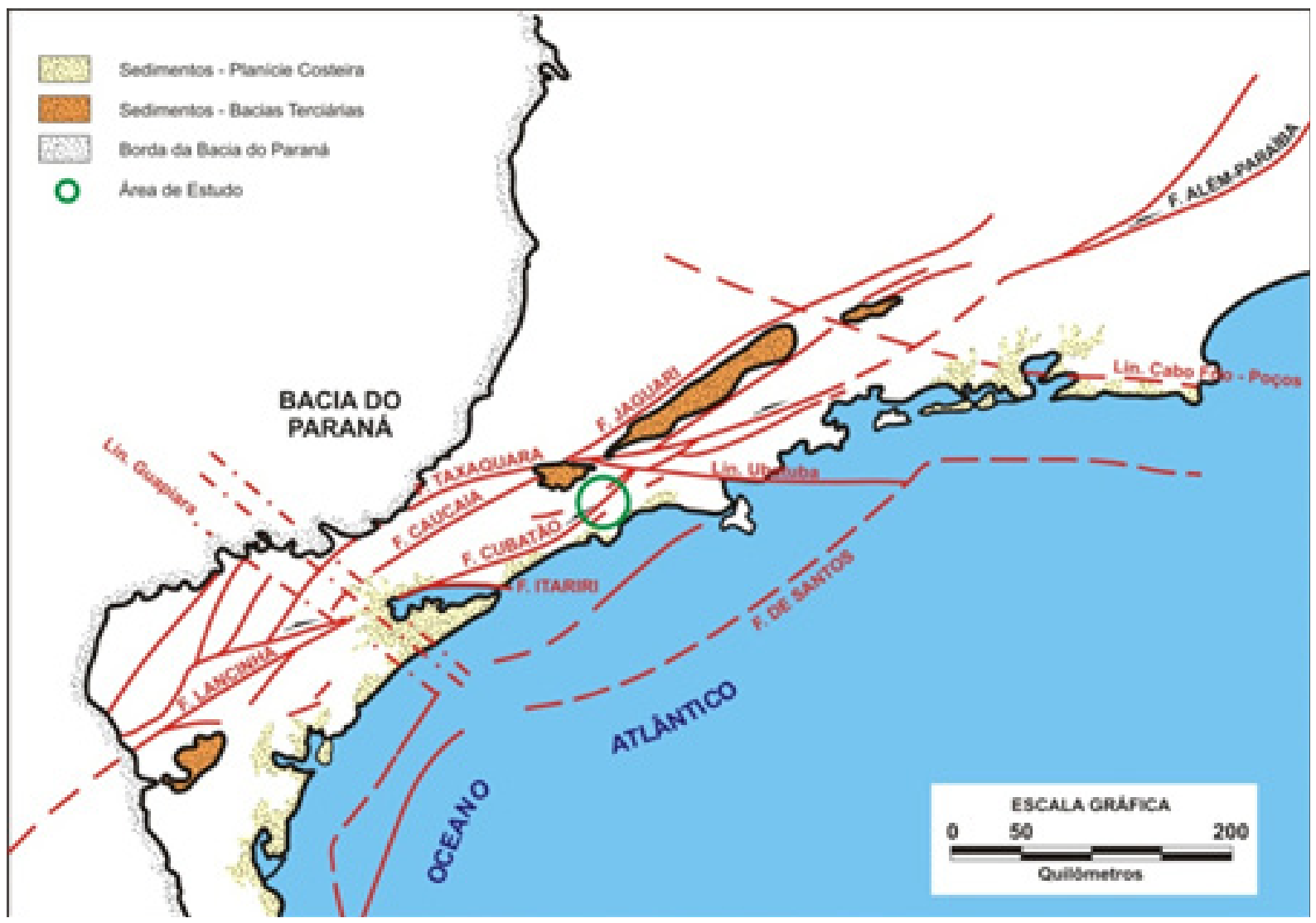

Figura 10. Contexto geotectônico da área de estudo. Fonte: Sadowski (1991)

As escarpas da Serra do Mar são sustentadas por rochas Pré-Cambrianas, ocorrendo, principalmente, migmatitos gnáissicos a xistosos.

Os sedimentos da Planície Sedimentar Costeira são formados por depósitos quaternários, em ambientes marinhos ou flúvio-lagunares e por depósitos detríticos de encosta (rampas de colúvio e leques aluviais), interdigitados a depósitos de mangues e aluviões atuais, conforme descrições apresentadas no Quadro 1.

As coberturas detríticas, que recobrem de modo irregular o sopé e a meia encosta das vertentes, constituem registros da atuação pretérita de fenômenos de movimentação de massas (escorregamentos, corridas de massas, entre outros).

Registra-se, ainda, a existência de morros-testemunho de rochas Pré-Cambrianas, remanescentes da erosão diferencial das escarpas da Serra do Mar, em meio aos sedimentos.

É importante registrar que, em toda a área de estudo, ocorrem aterros recentes (antrópicos) indiferenciados, capeando as unidades aqui descritas.

\subsection{GEOLOGIA E HIDROGEOLOGIA} LOCAL

Diante deste cenário de ampla complexidade geológica, a seguir é apresentada a caracterização dos diferentes hidrofácies identificados na área de estudo, para os quais foram adotadas características hidráulicas diferenciadas.

Diante desta realidade, para o entendimento das heterogeneidades que controlam o fluxo da água subterrânea local, fez-se necessário o aprimoramento do entendimento do arcabouço geológico local.

Com base nas características geológicas regionais e nas descrições obtidas por esta caracterização, conceitualmente, são distinguíveis cinco unidades hidrofaciológicas, conforme características descritas a seguir: 


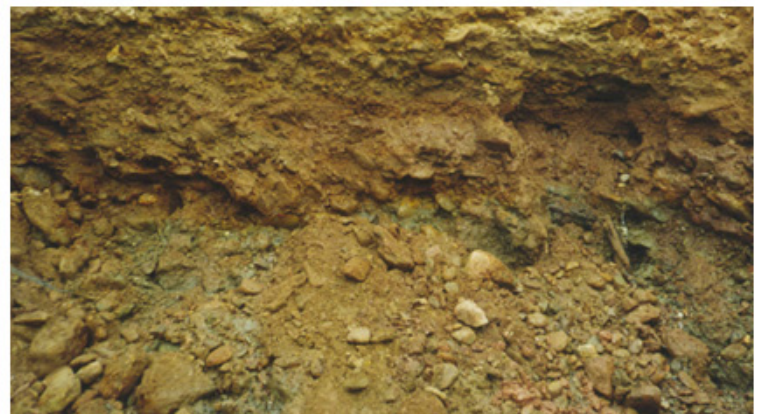

Hidrofácies Debris-Flows

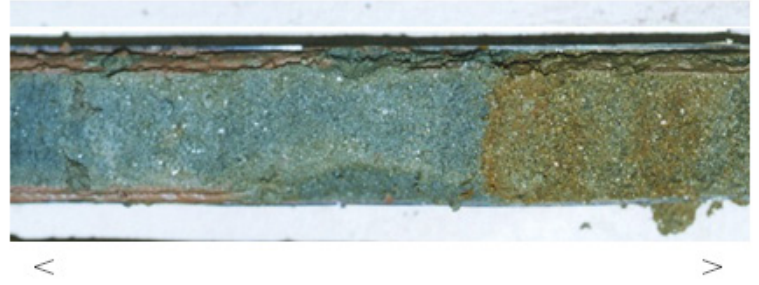

Granodecrescência observada no Hidrofácies Arenoso

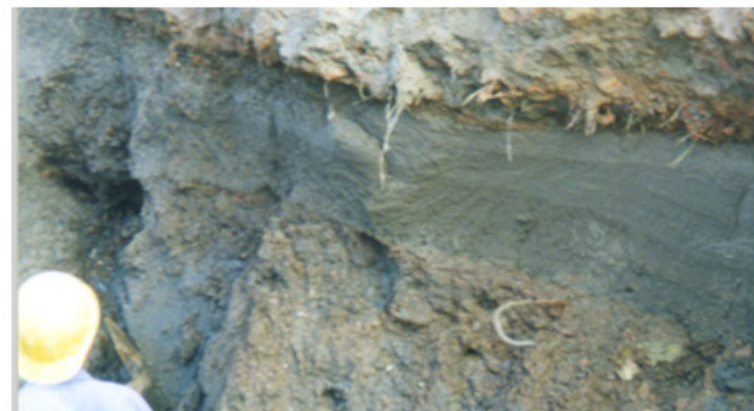

Hidrofácies Arenoso interdigitado ao Hidrofácies Debris-Flows

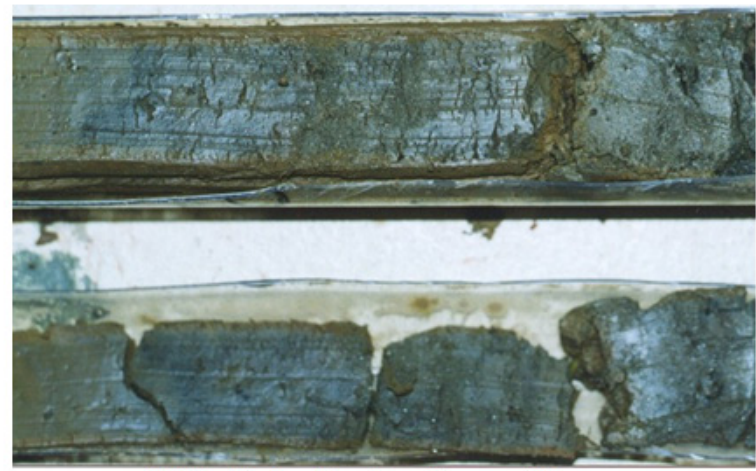

Hidrofácies Argilo-siltoso e Siltoso

Quadro 1. Características das unidades hidrofaciológicas sedimentares.

(I) Aterro: predominância de pedregulhos de dimensões variadas, com matriz arenosa ou siltoarenosa, porém, com variação textural pronunciada. Apresenta espessura média de $2,0 \mathrm{~m}$, podendo atingir até $8,0 \mathrm{~m}$ em alguns locais. A variação textural reflete em grande variedade nos valores de condutividade hidráulica, entre $10^{-6}$ e $10^{-3} \mathrm{~cm} / \mathrm{s}$;

\section{(II) Unidade Sedimentar Flúvio-Costeira: é} subdividida em:

a. Hidrofácies Arenoso: é representado por sedimentos com visíveis variações texturais, relacionadas à diversidade de processos deposicionais atuantes na gênese destes, predominando areias finas a médias, pouco a muito siltosas, normalmente intercaladas com lentes de sedimentos argilosos e siltosos, de coloração cinza, cinza escura ou amarela; apresentam espessuras centimétricas a métricas, com extensão lateral limitada, estando interdigitadas aos hidrofácies argilo-siltoso e a unidade de Debris-flows; os ensaios hidrogeológicos realizados neste hidrofácies mostraram valores entre $10^{-3}$ e $10^{-2} \mathrm{~cm} / \mathrm{s}$;

b. Hidrofácies Argilo-Siltoso: é constituído por sedimentos silto-arenosos, de coloração acinzentada, possivelmente representando depósitos de planícies de inundação, associados aos sedimentos arenosos de canais, e por sedimentos argilo-siltosos, silto-argilosos ou argilo-arenosos, de coloração cinza, preta ou esverdeada, apresentando abundante matéria orgânica e detritos vegetais; é predominante na área de estudo e apresenta espessuras maiores que $10,0 \mathrm{~m}$, espessando para sul; a condutividade hidráulica na área é reduzida, com valores entre $10^{-7}$ e $10^{-6} \mathrm{~cm} / \mathrm{s}$;

(III) Depósitos provenientes de movimentos gravitacionais de massa (debris-flows): estão geneticamente vinculados ao deslocamento de massas por processos gravitacionais, relacionados a eventos de elevado índice pluviométrico e às altas declividades das encostas da Serra do Mar; podem se interdigitar com depósitos fluviais e estuarinos; do ponto de vista textural, estes depósitos são representados por sedimentos arenosos conglomeráticos, mal selecionados, com seixos de dimensões centimétricas a decimétricas, em meio à matriz argilo-siltosa; os seixos deste hidrofácies são representados por fragmentos de rocha arredondados, com dimensões centimétricas à decimétricas, mostrando atuação intensiva de processos fluviais; estas características imprimem condutividades hidráulicas entre $10^{-5}$ e $10^{-3} \mathrm{~cm} / \mathrm{s}$, em virtude da matriz argilo-siltosa presente; 
(IV) Embasamento Cristalino Alterado: caracteriza-se por matriz predominantemente silto-arenosa ou areno-siltosa, coloração amarelada, cinza ou avermelhada, com blocos menos intemperizados, além de estruturas reliquiares herdadas da rocha matriz; a espessura do Embasamento Cristalino Alterado é amplamente variável, e pode alcançar até 28,0 m na porção centro-norte da área de estudo; apresenta variação de até 3 ordens de grandeza em seus valores de condutividade hidráulica, pelo diferenciado grau de intemperismo, sendo que em porções mais superficiais, ou seja, mais intemperizadas, apresentam condutividade hidráulica mais elevada, em torno de $10^{-3} \mathrm{~cm} / \mathrm{s}$, decrescendo progressivamente em profundidade, atingindo valores de até $10^{-6} \mathrm{~cm} / \mathrm{s}$, à medida que se aproxima do topo rochoso; $\mathrm{e}$

(V) Embasamento Cristalino São: compreende a base da estratigrafia local, representado predominantemente por rochas granito-gnáissicas e micaxistos, do Complexo Piaçaguera e Grupo Paraíbuna; a presença de fraturas e falhamentos é representativa, porém, suas características atribuem a estas litologias fluxo bastante limitado, conforme observado em afloramentos na área, que não apresentam significativo aporte de água em suas fraturas; estas características auxiliaram na definição de que esta litologia também é a base da hidrogeologia local.

A seção hidrofaciológica da Figura 11 mostra a distribuição vertical das unidades ao longo de uma seção N-S da área de estudo.

De acordo com os dados de carga hidráulica obtidos nos poços monitorados na área, entre setembro e outubro/2009, e os níveis dos rios e córregos presentes que cortam ou fazem limite com a área, o fluxo da água subterrânea ocorre predominantemente de norte para sul, com inflexões associadas à influência dos cursos d'água e pelas diferentes condutividades hidráulicas de cada unidade hidrofaciológica.

A feição regional de descarga das águas subterrâneas é o Rio Cubatão e, localmente, os cursos d'água que cortam a área de estudo, também representam feições de descarga, porém, com influência restrita a sua ocorrência. Altos do Embasamento Cristalino São geram restrições locais de fluxo, segmentando o aquífero em regiões com diferentes velocidades de fluxo.
A Figura 12 mostra o mapa potenciométrico da região, com indicação para a área de estudo, detalhada nesta pesquisa.

Em virtude das características faciológicas distintas e da potenciometria observadas na região, o cenário hidrogeológico se mostra bastante complexo, sendo difícil a definição determinística da distribuição espacial das propriedades hidráulicas.

Sendo assim, utilizou-se de simulações estocásticas para a realização de possíveis cenários de distribuição espacial das propriedades hidráulicas do meio e as simulações numéricas de fluxo da água subterrânea para a determinação das zonas de captura consequentes, para cada cenário geológico, conforme descrito a seguir.

\section{RESULTADOS OBTIDOS}

\subsection{Simulações estocásticas}

Para aplicação do método de definição da distribuição espacial das unidades hidrofaciológicas, foi selecionado um local da área de estudo, onde se pretende implantar uma barreira hidráulica para contenção de migração de contaminantes, por meio de bombeamento das águas subterrâneas da área. A Figura 13 apresenta a localização da área selecionada.

Foram gerados 10 cenários hidrofaciológicos, com distribuições espaciais distintas, respeitando-se o mesmo conjunto de dados litológicos obtidos de sondagens a percussão, os quais foram correlacionados aos dados de ensaios hidrogeológicos (tipo slug test) realizados, para determinação da condutividade hidráulica, em poços de monitoramento instalados na área de estudo, para definição das propriedades hidráulicas de cada um dos hidrofácies, conforme mostrado anteriormente.

Os hidrofácies considerados apresentaram a distribuição percentual mostrada na Tabela 1, no local selecionado, sendo respeitada esta distribuição em todas as simulações, o que significa que todos os cenários hidrofaciológicos apresentaram, em área, a mesma distribuição percentual entre os hidrofácies, mudando somente a sua localização.

Os hidrofácies foram numerados de 1 a 5 , conforme formato de entrada de dados do aplicativo T-PROGS, utilizado para as simulações. A Tabela 1 apresenta os hidrofácies considerados, os identificadores atribuídos e as frequências de distribuição de cada hidrofácies. 


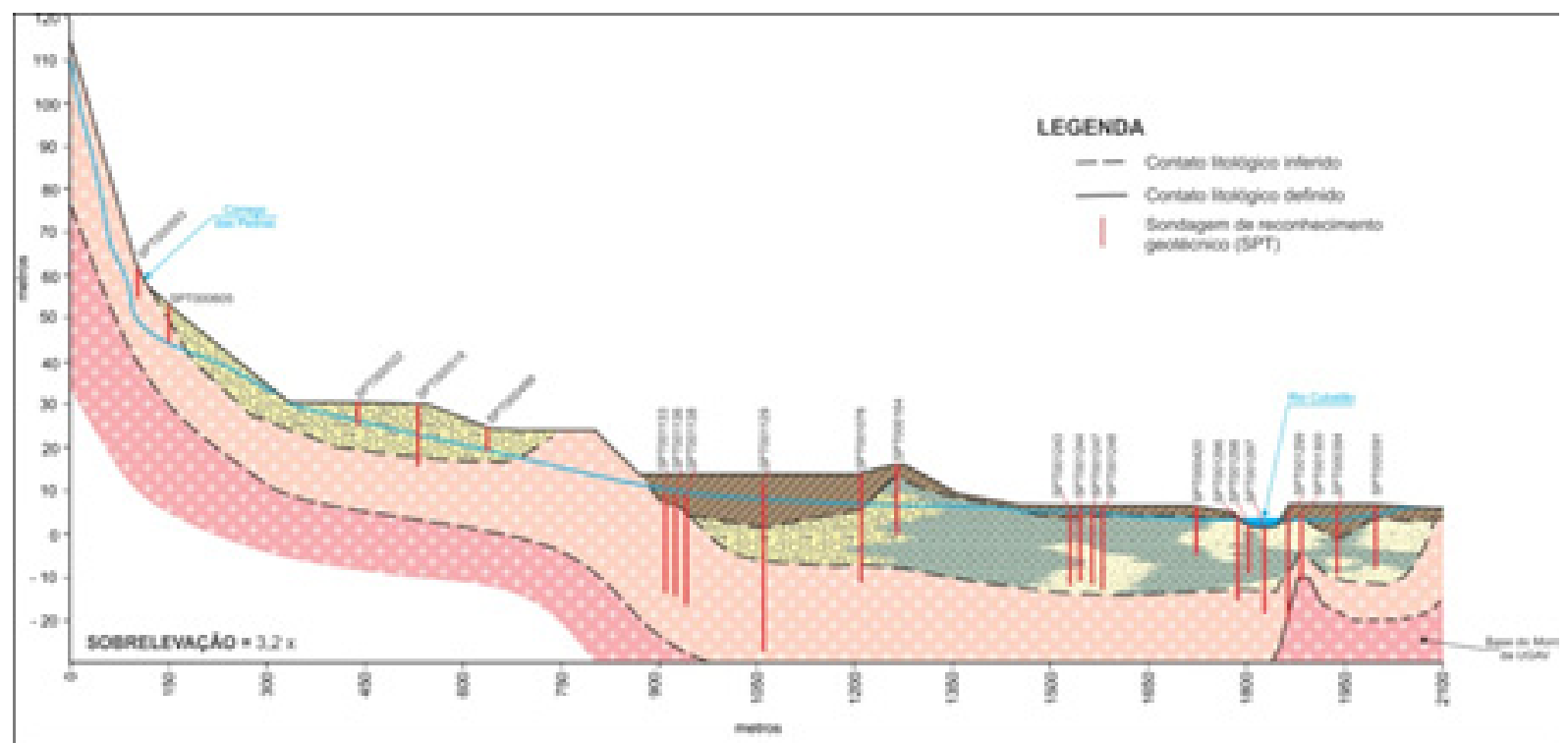

\section{UNIDADES LITOFACIOLOGICAS}
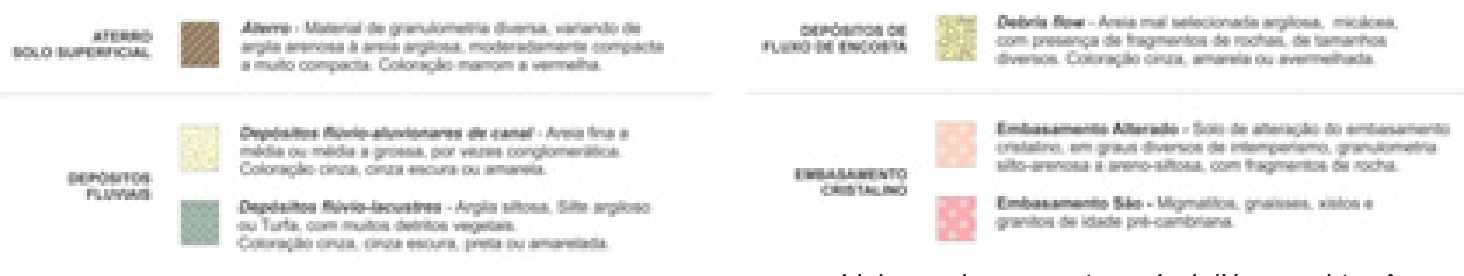

Linha azul representa o nível d’água subterrânea

Figura 11. Seção hidrofaciológica da área de estudo. Fonte: Alberto (2010).

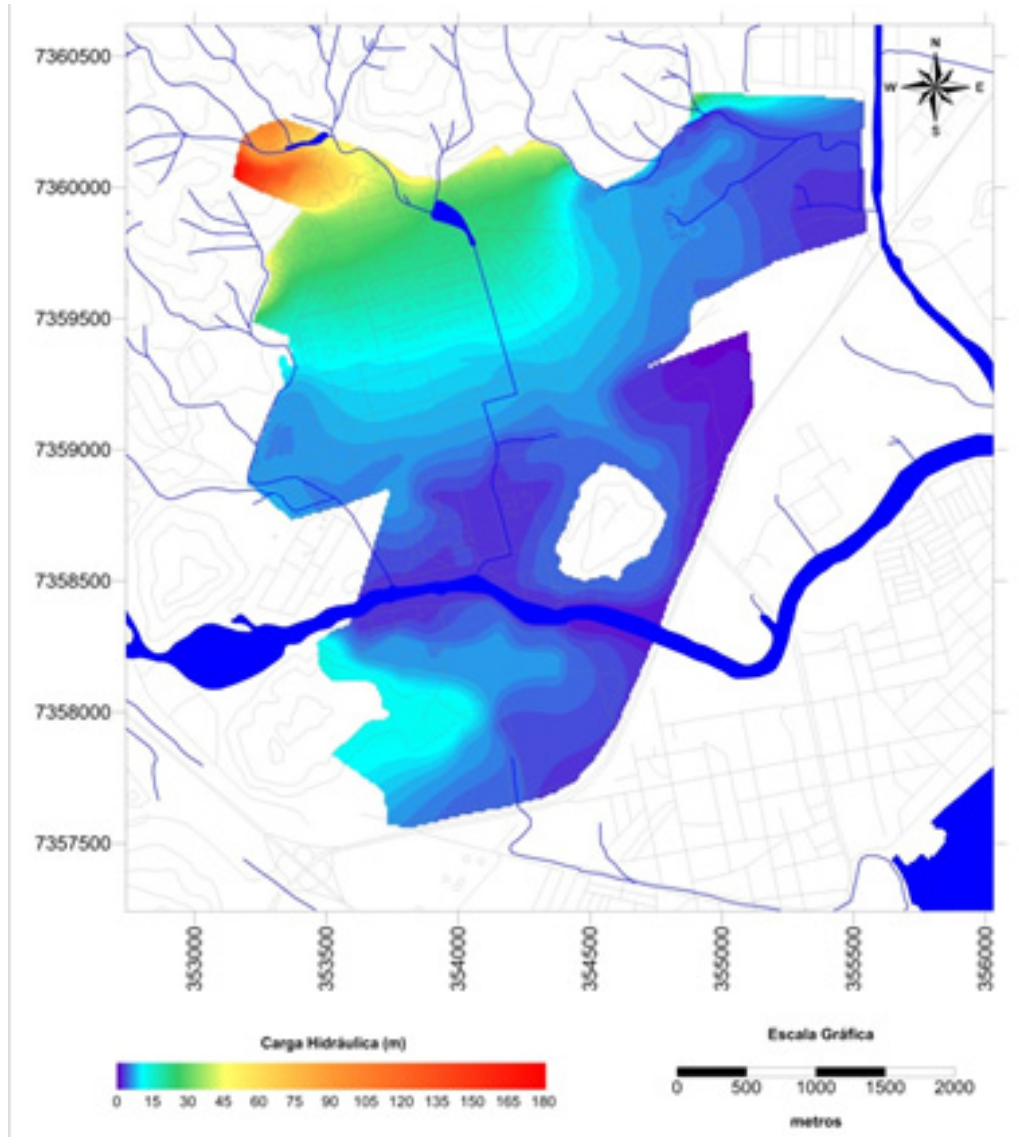




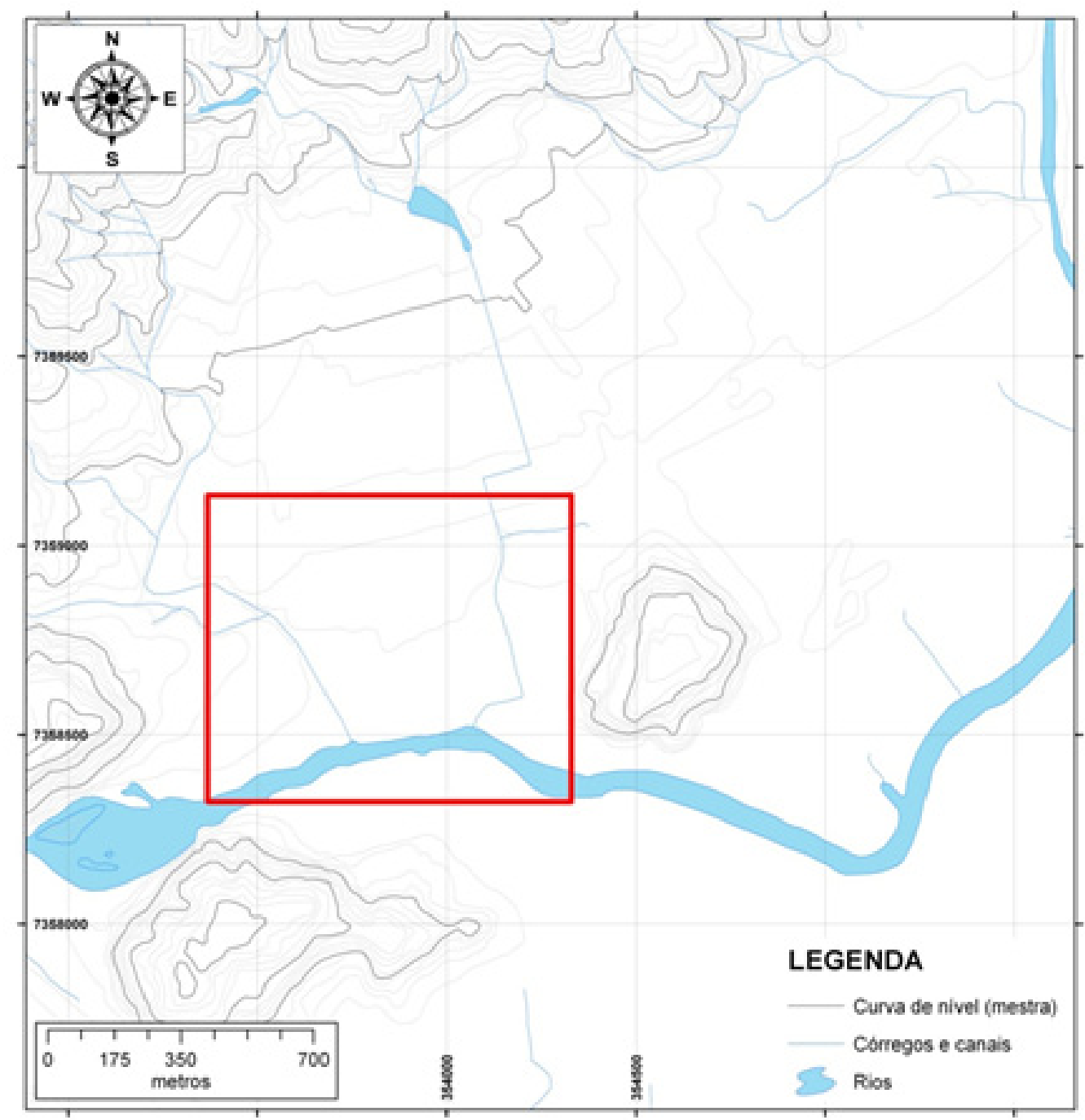

Figura 13. Localização da área selecionada para realização das simulações estocásticas.

Tabela 1. Distribuição de frequências dos hidrofácies do local selecionado e descrição das unidades

\begin{tabular}{|c|c|c|c|c|}
\hline IDENTIFICAÇÃO & UNIDADE & DESCRIÇÃO SUCINTA & $\begin{array}{l}\text { CONDUTIVIDADE } \\
\text { HIDRÁULICA }(\mathrm{m} / \mathrm{s})\end{array}$ & FREQUÊNCIA \\
\hline 1 & Areia Limpa & $\begin{array}{c}\text { Hidrofácies Arenoso - é } \\
\text { predominantemente constituída } \\
\text { por areias bem selecionadas, não } \\
\text { contendo, praticamente, argilas e/ } \\
\text { ou siltes }\end{array}$ & 6,91 & $24,0 \%$ \\
\hline 2 & $\begin{array}{l}\text { Areia com } \\
\text { finos }\end{array}$ & $\begin{array}{c}\text { Hidrofácies Arenoso - é } \\
\text { predominantemente constituída por } \\
\text { areias bem selecionadas, contendo } \\
\text { matriz argilosa a siltosa }\end{array}$ & 2,60 & $18,0 \%$ \\
\hline 3 & Argila & $\begin{array}{l}\text { Hidrofácies Argilo-Siltoso - é } \\
\text { predominantemente constituída por } \\
\text { argilas e, subordinadamente por } \\
\text { siltes }\end{array}$ & 0,0004 & $40,9 \%$ \\
\hline 4 & Debris Flows & $\begin{array}{l}\text { Hidrofácies Debris Flows - é } \\
\text { constituída por seixos, blocos e } \\
\text { matacões, envoltos por matriz } \\
\text { argilo-siltosa }\end{array}$ & 0,0432 & $8,1 \%$ \\
\hline 5 & Silte & $\begin{array}{l}\text { Hidrofácies Silto-Argiloso - é } \\
\text { predominantemente constituída por } \\
\text { siltes e, subordinadamente por siltes } \\
\text { argilosos e arenosos }\end{array}$ & 0,432 & $9,0 \%$ \\
\hline
\end{tabular}


Conforme se observa nesta tabela, é predominante a presença do Hidrofácies ArgiloSiltoso na área, seguido do Hidrofácies Arenoso (areia limpa e areia com finos)e, subordinadamente, ocorrendo o hidrofácies Debris flows. Este fato se deve ao local estar situado nas proximidades do Rio Cubatão e distante das encostas da Serra do Mar, predominando sedimentos aluvionares, representantes de paleocanais deste rio e áreas de várzea do mesmo.

Com base nestes dados, e nos parâmetros apresentados na Tabela 2, foram calculadas as matrizes de probabilidade de transição vertical entre as unidades, conforme curvas de correlação apresentadas na Figura 14, sendo obtidos os comprimentos máximos verticais das lentes de cada unidade hidrofaciológica, de acordo com cadeias de Markov, mostrados na Tabela 3.

O espaçamento do passo vertical foi considerado tendo em vista a espessura mínima, centimétrica, das unidades, para permitir a avaliação detalhada da variação vertical. A máxima distância de cada passo (ou lag) foi calculada com base no espaçamento do passo vertical, e foram considerados 10 passos, tendo em vista a distância entre as sondagens utilizadas poder ser superior a 50,0 m entre si, em alguns casos.

As taxas de probabilidade de transição vertical e horizontais calculadas são apresentadas nas Tabelas 4 e 5.

Com base nas taxas de probabilidade de transição vertical e horizontais calculadas, foram simuladas 10 realizações, gerando 10 conjuntos de distribuição espacial dos hidrofácies no local selecionado, conforme mostrado na Figura 15. As realizações foram denominadas de Simulação 1 a 10.

\subsection{Zonas de captura}

A partir destes dez cenários obtidos por meio das simulações estocásticas, foram realizadas simulações numéricas do fluxo da água subterrânea, com um poço em bombeamento, para avaliação das possíveis configurações espaciais da zona de captura deste bombeamento, comparando-se as diferenças obtidas para cada cenário.

As simulações foram realizadas em regime transiente de fluxo para um período de 365 dias, sendo avaliada a zona de captura no $150^{\circ}$ dia, escolhido arbitrariamente. O aplicativo para realização das simulações numéricas foi o Visual MODFLOW v. 4.2. da Schlumberger, Inc. (2008).

Para as simulações foi considerada condição de contorno de $1^{\circ}$ tipo (carga hidráulica especificada) na extremidade norte do modelo, tendo em vista a pouco significativa variação do nível d'água nesta porção do modelo. Para a extremidade sul foi utilizado o Pacote River, representando o rio Cubatão, o qual apresenta gradiente baixo. Para os limites laterais, leste e oeste, foram consideradas condições de contorno de fluxo nulo, acompanhando as linhas de fluxo desta porção.

A malha utilizada para simulação foi configurada com espaçamento de 2,0 m para cada célula, contendo 365 × 350 células, em uma área de 730 x $700 \mathrm{~m}$, sendo que este espaçamento foi considerado para compatibilizar ao máximo possível o tamanho da célula com a existência de um poço, o qual assume o tamanho da célula em que foi posicionado. Para este poço foi considerada vazão de $240,0 \mathrm{~L} / \mathrm{h}$, conforme dados obtidos de teste realizado na área de estudo, com seção filtrante plena, sendo que a espessura do modelo foi considerada constante de $6,0 \mathrm{~m}$, tendo em vista o fluxo da água subterrânea mostrar-se predominante nas porções superficiais do aquífero.

Tabela 2. Parâmetros utilizados para o cálculo da probabilidade de transição vertical

\begin{tabular}{|l|c|}
\hline \multicolumn{1}{|c|}{ PARÂMETRO } & VALOR CONSIDERADO \\
\hline Espaçamento do passo vertical (vertical lag spacing) & $0,3 \mathrm{~m}$ \\
\hline $\begin{array}{l}\text { Máxima distância do passo (maximum lag distance) - } \\
\text { calculado pelo modelo, com base no espaçamento vertical }\end{array}$ & $6,3 \mathrm{~m}$ \\
\hline Ajuste de curvas & 10 passos (lags) \\
\hline
\end{tabular}

Tabela 3. Comprimentos verticais máximos de lentes de cada unidade hidrofaciológica

\begin{tabular}{|l|c|}
\hline \multicolumn{1}{|c|}{ UNIDADE } & COMPRIMENTO VERTICAL \\
\hline Hidrofácies Arenoso - Areia limpa & $3,5 \mathrm{~m}$ \\
\hline Hidrofácies Arenoso - Areia com finos & $2,0 \mathrm{~m}$ \\
\hline Hidrofácies Argiloso - Argila & $4,0 \mathrm{~m}$ \\
\hline Hidrofácies Debris flows - Debris & $3,6 \mathrm{~m}$ \\
\hline Hidrofácies Siltoso - Silte & $2,5 \mathrm{~m}$ \\
\hline
\end{tabular}


Tabela 4. Taxas de probabilidade de transição para o eixo vertical (Z)

\begin{tabular}{|c|c|c|c|c|c|}
\cline { 2 - 6 } \multicolumn{1}{c|}{} & $\mathbf{1}$ & $\mathbf{2}$ & $\mathbf{3}$ & $\mathbf{4}$ & $\mathbf{5}$ \\
\hline $\mathbf{1}$ & -0.2864236 & 0.04751351 & 0.16989093 & 0.07772101 & -0.0087017 \\
\hline $\mathbf{2}$ & 0.07259067 & -0.4910836 & 0.25517417 & 0.05845395 & 0.10486489 \\
\hline $\mathbf{3}$ & 0.12845696 & 0.08161772 & -0.2541108 & -0.0083940 & 0.0524303 \\
\hline $\mathbf{4}$ & -0.0239181 & 0.07453539 & 0.25948152 & -0.2742820 & -0.0358167 \\
\hline $\mathbf{5}$ & 0.05574927 & 0.41135058 & -0.0322393 & -0.0400428 & -0.3948178 \\
\hline
\end{tabular}

Tabela 5. Taxas de probabilidade de transição para os eixos horizontais (X e Y)

\begin{tabular}{|c|c|c|c|c|c|}
\cline { 2 - 6 } \multicolumn{1}{c|}{} & $\mathbf{1}$ & $\mathbf{2}$ & $\mathbf{3}$ & $\mathbf{4}$ & $\mathbf{5}$ \\
\hline $\mathbf{1}$ & -0.0286423 & 0.00245637 & 0.0218988 & 0.00269512 & 0.00159208 \\
\hline $\mathbf{2}$ & 0.00330311 & -0.0491083 & 0.03983824 & 0.00128492 & 0.00468209 \\
\hline $\mathbf{3}$ & 0.0128036 & 0.0173214 & -0.0389906 & 0.00324042 & 0.00562526 \\
\hline $\mathbf{4}$ & 0.0080412 & 0.00285095 & 0.01653605 & -0.0274282 & 0 \\
\hline $\mathbf{5}$ & 0.00427746 & 0.00935476 & 0.02584955 & 0 & -0.0394817 \\
\hline
\end{tabular}

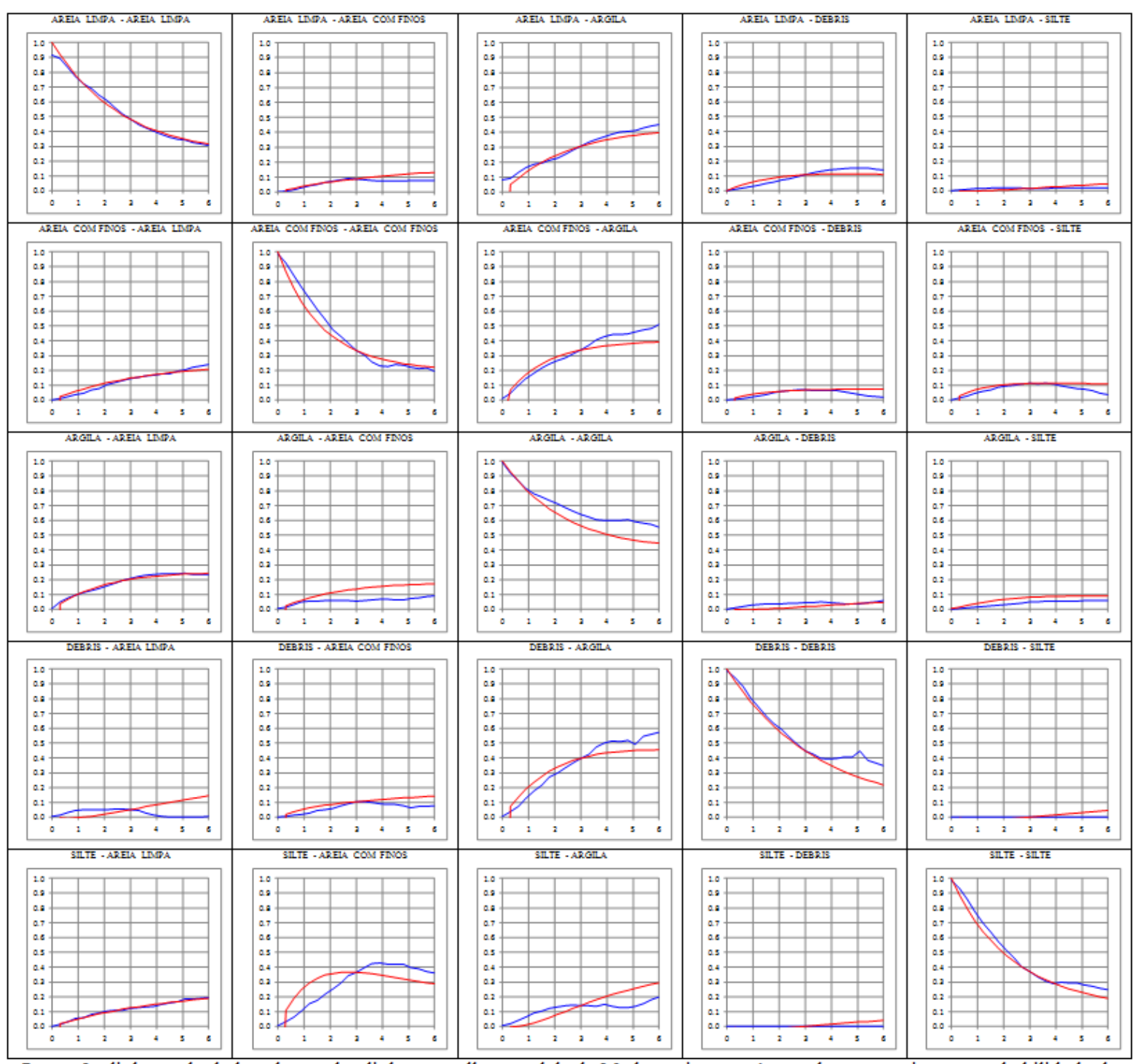

Legenda: linha azul - dados observados; linha vermelha - modelo de Markov; eixox - número de passos; eixo y - probabilidade de transição.

Figura 14. Curvas de probabilidade de transição calculadas e ajustadas para o local selecionado. 

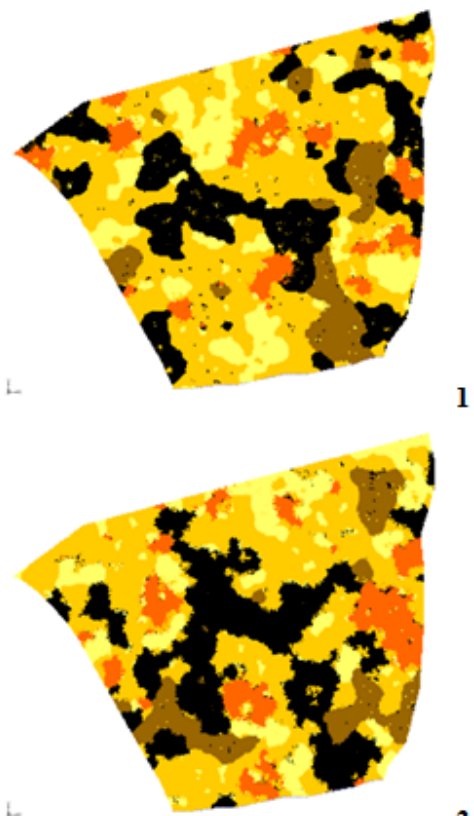

3
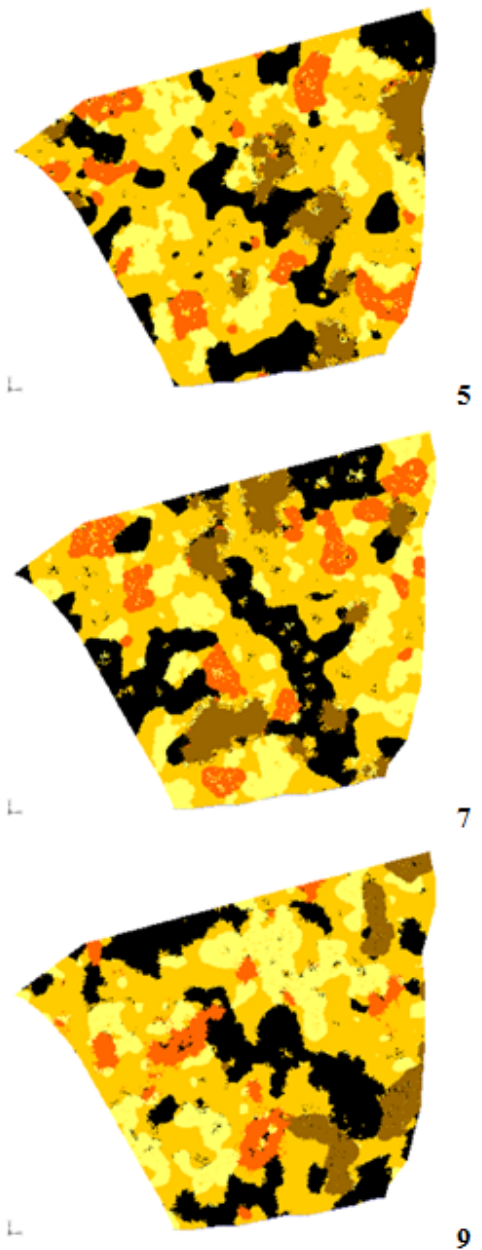
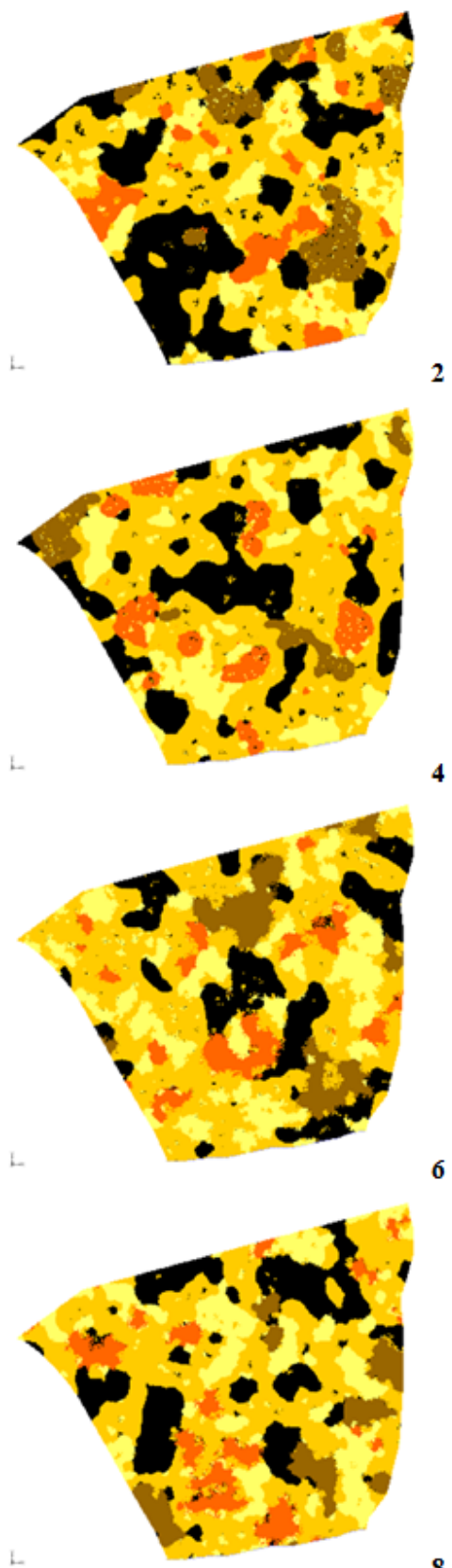

8

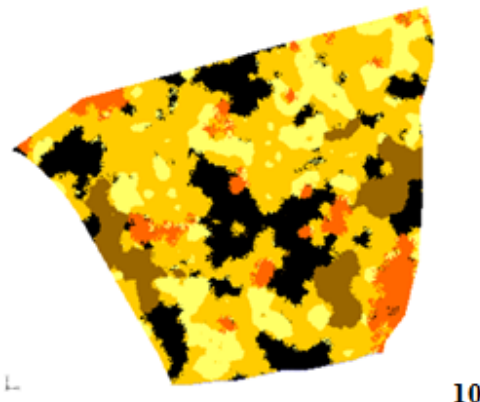

10

Legenda: Preto - areia limpa; Amarelo claro - areia com finos; Laranja claro - argila; Laranja escuro - silte; Ocre - debris flows)

Figura 15. Distribuição espacial dos hidrofácies para as dez realizações das simulações estocásticas. 
A Figura 16 mostra o domínio modelado e as condições de contorno utilizadas.

Os resultados das simulações numéricas para determinação da configuração das zonas de captura são descritos na Tabela 6, e a configuração espacial das mesmas é mostrada na Figura 17.

\section{CONSIDERAÇÕES FINAIS}

De acordo com os resultados obtidos pelas simulações realizadas na área de estudo, quanto à hidrogeologia e ao dimensionamento da zona de captura de um poço de bombeamento, visando à configuração de uma barreira hidráulica, verificou-se que:

- a configuração espacial das zonas de captura de um poço em bombeamento é bastante diferenciada, de acordo com os diferentes cenários de distribuição das litologias simuladas, sendo mais expressivas quando o fluxo da água subterrânea é condicionado por litologias arenosas, e pouco expressivos quando se observa a presença de litologias argilosas a siltosas;

- Estas distintas configurações demonstram que a heterogeneidade litológica imprime incertezas na definição de um projeto de remediação que utilize o bombeamento das águas subterrâneas, podendo, inclusive, subestimar ou superestimar a captura de um determinado contaminante, consequentemente, elevando os custos de remediação ou permitindo a exposição de eventuais receptores, quando estes contaminantes não são devidamente capturados pelo bombeamento;

- Não somente a configuração do formato das zonas de captura é afetado, mas também a intensidade do rebaixamento, o qual é limitado em corpos arenosos e mais acentuados em corpos litológicos argilo-siltosos, que, a depender do tipo de substância em remediação, pode trazer prejuízos na projeção de um sistema de remediação.

- Em escala de detalhe, é importante a visualização das diferentes possibilidades de distribuição das litologias presentes, utilizando-se métodos probabilísticos, pois, as distintas combinações espaciais das litologias condicionam, consideravelmente, o fluxo da água subterrânea e, consequentemente, o formato, extensão e intensidade das zonas de captura do bombeamento de águas subterrâneas.

- A ampla disparidade nas respostas obtidas pelos diferentes cenários simulados revela uma situação dominada por incertezas, no que se refere ao conhecimento geológico de subsuperfície, face à forte heterogeneidade litológica local. Este fato reforça a necessidade de investigações com elevado grau de detalhamento, de modo a minimizar as incertezas no dimensionamento inadequado dos sistemas de remediação.

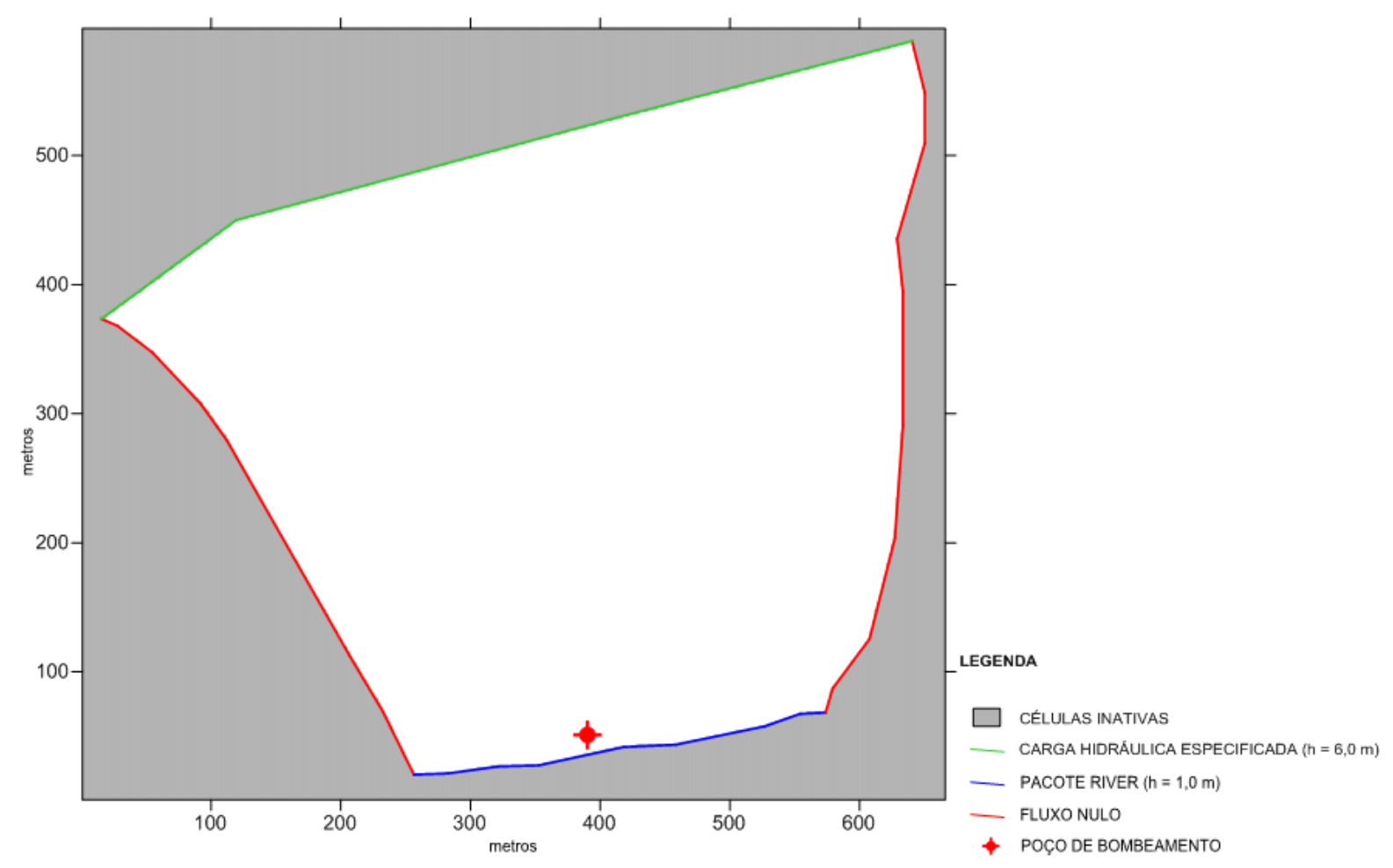

Figura 16. Domínio do modelo e condições de contorno. 

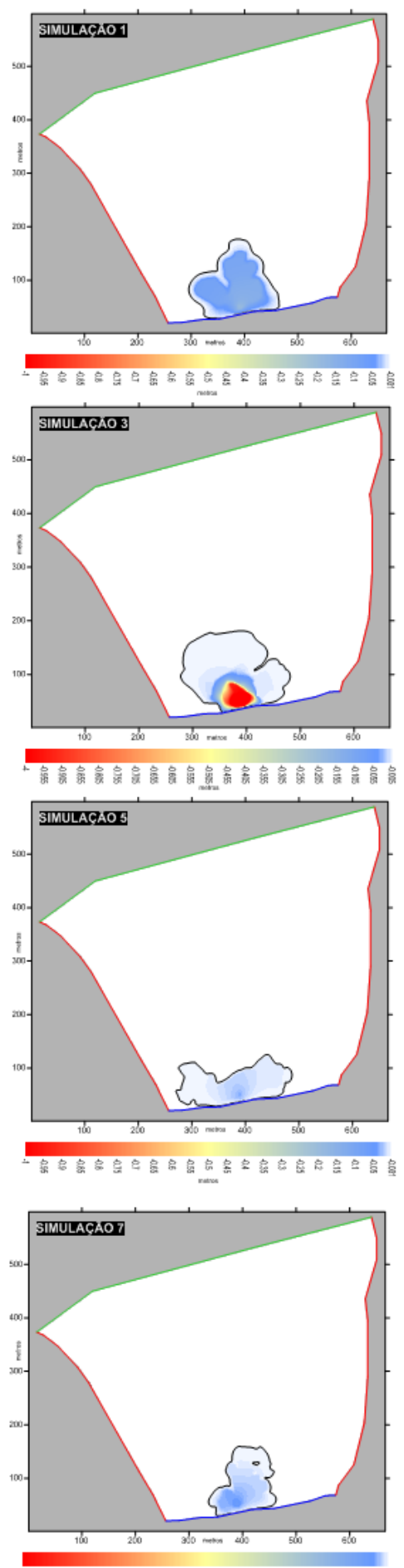

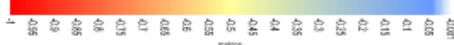

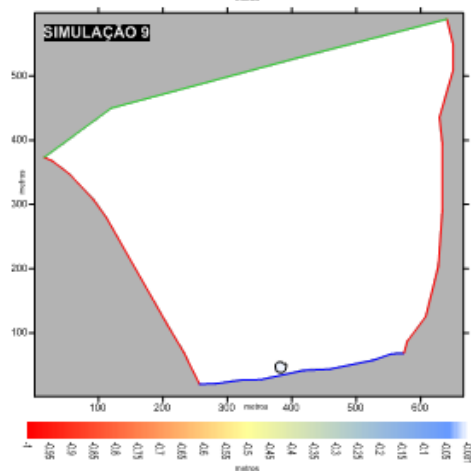

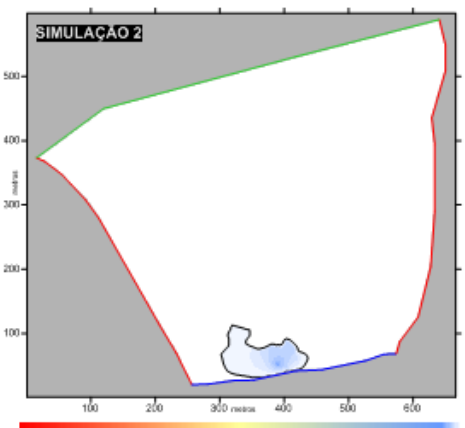
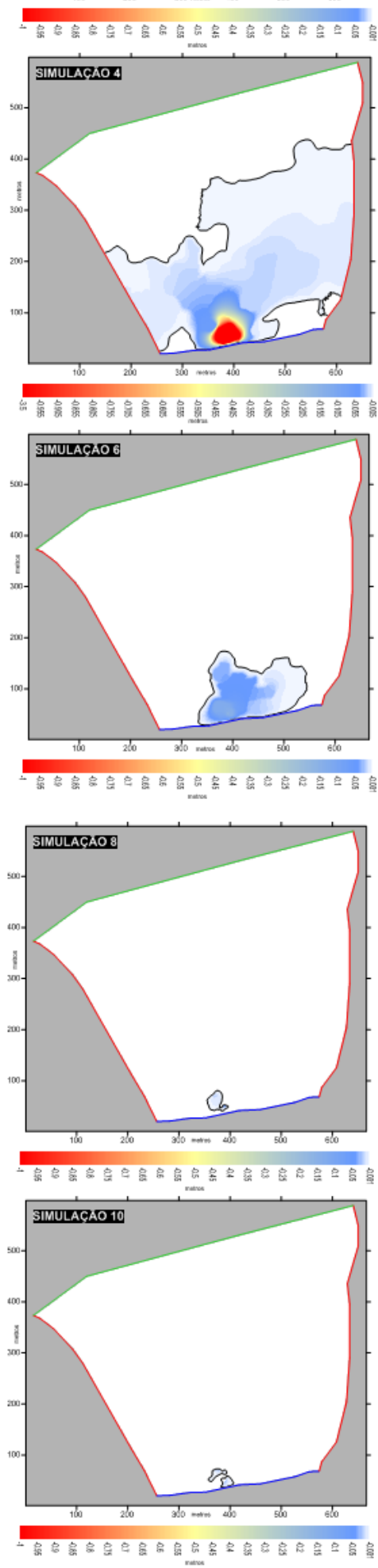

Figura 17. Zonas de captura obtidas pelas simulações numéricas para cada realização estocástica 
Tabela 6. Descrição das zonas de captura

\begin{tabular}{|c|c|}
\hline SIMULAÇÃO & DESCRIÇÃO \\
\hline 1 & $\begin{array}{l}\text { A zona de captura é fortemente condicionada pelo corpo de areia com finos, presente nas proximidades do poço } \\
\text { de bombeamento, apresentando rebaixamento não superior a } 0,4 \mathrm{~m} \text {. O comprimento maior da zona de captura tem } \\
150,0 \text { m longitudinalmente ao fluxo da água subterrânea. }\end{array}$ \\
\hline 2 & $\begin{array}{l}\text { Para este cenário, a configuração da zona de captura mostra comprimento maior transversal à direção de fluxo } \\
\text { da água subterrânea, com aproximadamente } 120,0 \mathrm{~m} \text { de comprimento, condicionado pelos corpos de areia } \\
\text { limpa e areia com finos, presentes a oeste do poço em bombeamento, não apresentando rebaixamento superior a } \\
0,2 \mathrm{~m} \text {. }\end{array}$ \\
\hline 3 & $\begin{array}{l}\text { Para este cenário observa-se zona de captura mais abrangente, provavelmente pela presença de frações } \\
\text { granulométricas mais finas, bem como pela presença de matriz silto-argilosa. O rebaixamento observado é } \\
\text { superior a } 3,0 \mathrm{~m} \text { nas proximidades imediatas ao poço, associada à litologia siltosa presente no local onde foi } \\
\text { inserido este poço. }\end{array}$ \\
\hline 4 & $\begin{array}{l}\text { A zona de captura, nas proximidades do poço apresenta comportamento similar ao Cenário 3, porém, a sua } \\
\text { abrangência é muito maior, extrapolando os limites físicos da área. Isto se deve a pouca ocorrência de corpos } \\
\text { arenosos na porção sul deste arranjo, situadas na porção central a centro-norte do local. O rebaixamento observado } \\
\text { é superior a } 3,0 \text { m conforme observado para o cenário } 3 \text {. A abertura das Zonas de Captura (ZCs), para leste e oeste, } \\
\text { estão diretamente condicionadas por corpos de maiores granulometrias (corpos arenosos limpos e com finos). }\end{array}$ \\
\hline 5 & $\begin{array}{l}\text { A ZC deste cenário tem um comportamento bastante semelhante àquele do Cenário } 2 \text {, porém, apresenta maior } \\
\text { abrangência lateral em relação ao cenário } 2 \text {, condicionado ao corpo de areia limpa alinhado a extremidade sul da } \\
\text { área avaliada, apresentando rebaixamentos inferiores a } 0,1 \mathrm{~m} \text {. }\end{array}$ \\
\hline 6 & $\begin{array}{l}\text { A ZC deste arranjo espacial das condutividades hidráulicas está diretamente associada aos corpos arenosos } \\
\text { presentes na porção sul da área avaliada, sendo que, na parte centro-sul, está um corpo arenoso com finos e para } \\
\text { leste ocorre um corpo de areia limpa, assim como um corpo de debris flows. O rebaixamento máximo observado } \\
\text { para este cenário é de } 0,35 \mathrm{~m} \text {. }\end{array}$ \\
\hline 7 & $\begin{array}{l}\text { A ZC simulada para este cenário mostra-se similar àquela do cenário } 6 \text {, exceto pelo fato de que está limitada } \\
\text { para leste, pela existência de corpos argilosos para esta direção. Outra diferença em relação ao cenário } 6 \text { é o } \\
\text { rebaixamento que naquele caso ocorre até } 0,35 \mathrm{~m} \text {, e neste cenário apresenta rebaixamento de no máximo } 0,1 \mathrm{~m} \text {. }\end{array}$ \\
\hline 8 a 10 & $\begin{array}{l}\text { Estes cenários apresentaram respostas bastante similares em relação à configuração das suas respectivas zonas } \\
\text { de captura, pois, nas simulações estocásticas, se registram somente corpos argilosos e siltosos, não permitindo } \\
\text { grandes zonas de captura. }\end{array}$ \\
\hline
\end{tabular}

- A utilização de modelos estocásticos permite inferir, qualitativamente e quantitativamente, o grau de incertezas existente na área onde se deseja implantar um sistema de remediação, em função da quantidade e distribuição das informações disponíveis. A existência de variações significativas nas respostas dos sistemas de remediação, verificadas pelos modelos estocásticos, revela a necessidade de aquisição de informações adicionais, tendo em vista que as incertezas presentes são significativas e a eficiência das técnicas de remediação propostas não podem ser asseguradas e dependem de informações detalhadas e de qualidade.

\section{AGRADECIMENTOS}

Os autores agradecem à FUNDUNESP e a PETROBRAS por permitirem a realização desta pesquisa.

\section{REFERÊNCIAS}

AHERN, J. A.; LILLY, M. R.; HINZMAN, L. D. Ground-Water Capture Zone Delineation of Hypothetical Systems: Methodology Comparison and Real-World Applications. American Geophysical Union, Fall Meeting, 2003.

ALBERTO, M.C. Heterogeneidades geológicas e o gerenciamento de áreas contaminadas em local situado na interface da Serra do mar com a Planície Aluvionar do Rio Cubatão (Cubatão/ SP). Tese de Doutoramento, Orientador: Prof. Chang Hung Kiang, Instituto de Geociências e Ciências Exatas - IGCE, Universidade Estadual Paulista - UNESP, 2010.

ALMEIDA F. F. M. de. Origem e Evolução da

Plataforma Brasileira., Rio de Janeiro: $36 \mathrm{p}$. Águas Subterrâneas, v.25, n.1, p.121-142, 2011
Departamento Nacional de Produção Mineral B. Divisão de Geologia e Mineralogia, ${ }^{\circ}$ 241, 1976.

CARLE, S.F. T-PROGS: Transition Probability Software v2.1. Hydrologic Sciences Graduate Group, University of California, 1999.

CARLE, S.F. \& FOGG, G.E. Modeling spatial variability with one- and multidimensional continuous-lag Markov chains. Mathematical Geology, v. 29, (2): p. 891-917, 1997.

CHANG HK, KOWSMANN RO, FIGUEREDO AMF \& BENDER AA. 1992. Tectonics and stratigraphy of the East Brazil rift system: an overview. Tectonophysics, 213: 97-138.

COLE, B. E. \& SILLIMAN, S. E. Utility of Simple Models of Capture Zone Delineation 
in Heterogeneous Unconfined Aquifers. Groundwater, v.38(5): p. 665-672, 2000.

COPTY, N. K. \& FINDIKAKIS, A. N. Uncertainty analysis of a well capture zone under multiple scales of heterogeneity. Calibration and Reliability In Groundwater Modelling: A Few Steps Closer to Reality. Proceedings of ModelCARE/2002. Prague. Czech Republic. June 2002. IAHS Publ. no. 277, 2002.

ELFEKI, A.M.M.; UFFINK, G.J.M. \& BARENDS, F.B.J. Groundwater Contaminant Transport: Impact of Heterogeneous Characterization. ISBN 905410665 4. A.A. Balkema, Rotterdam, Netherlands, 1997.

HASUI, Y; MIOTO, J.A. \& MORALES, N. Geologia do Pré-Cambriano. In: A. Negrão Jr., A.A. Ferreira, R. Alonzo, P.A.C. Luz, F.F. Falconi, R.Q. Frota (Coordenadores), Solos do Litoral de São Paulo. São Paulo, Associação Brasileira de Mecânica de Solos. p. 41-67, 1995.

INDELMAN, P. LESSOFF, S.C., DAGAN, G.. Analytical solution to transport in threedimensional heterogeneous well capture zones. Journal of Contaminant Hydrology 87: p. 1-21, 2006.

KINZELBACH, W.; VASSOLO, S. \& LI, G.M. Determination of capture zones of wells by Monte Carlo simulation. Calibration and Reliability in Groundwater Modelling (Proceedings of the ModelCARE96Conference held at Golden, Colorado, September 1996). IAHS Publ. no. 237, 1996.

LU, Z. M. \& ZHANG, D. X. On stochastic study of well capture zones in bounded, randomly heterogeneous media. Water Resources Research, v. 39 (4): p. 1100-1111, 2003.

LU, Z. M.; HIGDON, D. M. \& ZHANG, D. X. A Markov Chain Monte Carlo Method for the Groundwater Inverse Problem. 15th International Conference on Computational Methods in Water Resources. 2000.

RICCOMINI, C. Tectônica e sedimentação no sistema de rifts continentais da Serra do mar (bacias de Volta Redonda, Resende, Taubaté e São Paulo). In: Simpósio de Geologia, 1. Anais, Rio de Janeiro, SBG, p. 253-298, 1987. RIJUD, N. C.; HARTER, T.; WEISSMANN, G. S. \& FOGG, G. E. Conditional geostatistical modelling of an alluvial aquifer system characterized by poor-quality shallow groundwater. Calibration and Reliability in Groundwater Modelling, Proceedings of the ModelCARE'99 Conference, Zurich,
Switzerland, September 1999. IAHS Publication $n^{\circ} 265,2000$.

SADOWSKI, G. R. A Megafalha de Cubatão no Sudeste Brasileiro. Boletim IG-USP, Série Científica, vol 22: p. 15-28, 1991.

SADOWSKI, G. R. \& MOTIDOME, M. Brazilian Megafaults. Revista Geologica del Chile, v. 31, n. Especial, p. 61-75, 1987.

SHARP JR., J.M.; SHI, M. \& GALLOWAY, W.E. Heterogeneity of fluvial systems - control on density-driven flow transport. Environmental \& Engineering Geology, vol IX (1): p. 5-17. Association of Engineering Geologists, Geological Society of America, Feb/2003.

SUGUIO, K. \& MARTIN, L. Geologia do Quaternário. In: FALCONNI, F.F. \& NIGRO JR., A. Solos do Litoral Paulista. ABMS/São Paulo, p. 69-97, 1994.

UNITED STATES ENVIRONMENTAL PROTECTION AGENCY - USEPA. A Systematic Approach for Evaluation of Capture Zones at Pump and Treat Systems. Final Project Report. Publicação no EPA/600/R-08/003, Jan/2008.

VAN LEEUWEN, M.; BUTLER, A. P.; TOMPKINS, J. A. \& STROET, C. B. M. TE. Stochastic well capture zones in fully, leaky, and randomly confined, heterogeneous aquifers. Calibration and Reliability In Groundwater Modelling (Proceedings of the ModelCARE 99 Conference held at Zurich, Switzerland, September 1999). IAHS Publ. no. 265, 2000.

WEISSMANN, G.S. Application Of Transition Probability Geostatistics In A Detailed Stratigraphic Framework. ThreeDimensional Geological Mapping for Groundwater Applications Workshops, 2005. Disponível em http://www.isgs.illinois. edu/research/3DWorkshop/2005/pdf-files/ weissman2005.pdf

ZHANG, D. X. \& LU, Z. M.. Stochastic delineation of well capture zones. Stochastic Environmental Research and Risk Assessment Volume 18, Number 1, 39-46, 2004

\section{Fontes eletrônicas:}

EMS-I. Manual eletrônico do T-PROGS. http:// www.ems-i.com/gmshelp/Interpolation/TPROGS/T-PROGS_Interface.htm. Consultado em 21/04/2011

EMS-I. Manual eletrônico do T-PROGS. http:// www.ems-i.com/gmshelp/Interpolation/TPROGS/T-PROGS_Interface.htm. Consultado em 21/04/2011.

Águas Subterrâneas, v.25, n.1, p.121-142, 2011 